Supplement of Earth Surf. Dynam., 9, 253-269, 2021 https://doi.org/10.5194/esurf-9-253-2021-supplement (C) Author(s) 2021. CC BY 4.0 License.

(c) (i)

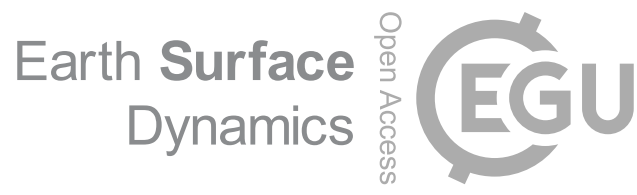

Supplement of

\title{
Laboratory observations on meltwater meandering rivulets on ice
}

\author{
Roberto Fernández and Gary Parker \\ Correspondence to: Roberto Fernández (r.fernandez@hull.ac.uk)
}

The copyright of individual parts of the supplement might differ from the article licence. 


\section{Supplementary Material}

\section{Section S1: Extended Methodology}

\section{Centimeter Scale Experiments}

An ice block is made by filling a lidless cooler with tap water and placing it inside a chest freezer. The interior dimensions of the cooler are $\mathrm{L}=0.96 \mathrm{~m}, \mathrm{D}=\mathrm{W}=0.38 \mathrm{~m}$ and can hold a maximum volume of approximately $0.140 \mathrm{~m}^{3}$. The chest freezer is allowed to reach its minimum temperature of $-15{ }^{\circ} \mathrm{C}$ which takes 5-7 days depending on outside temperature conditions and initial water temperature. Once this temperature is reached, the ice block is ready to conduct an experiment. To run an experiment, the cooler is taken out of the chest freezer and left at room temperature until the ice block comes loose and may be slid out of the cooler. In a room at $20^{\circ} \mathrm{C}$, the waiting time is 1-2 hours and depends on the dimensions of the block. Shorter waiting times are associated with small ice block thickness and vice versa. Within this waiting period, a rivulet is carved on the surface of the ice block with a chisel. After the ice block is taken out of the cooler, it is placed on the floor with the setup shown in Figure 2.

Elevations along the carved rivulet and the ice surface are measured with a point gage. This is done before the run and at different times during the run to measure channel slope. A Mariotte bottle, i.e. a device that delivers a constant rate of flow from a closed container, is used as the inflow source for the experiments. The Mariotte bottle used was made from a commercially available 18.9 L water jug. Water inside the Mariotte bottle is filled with ice cubes right before the run and then tap water is added.

Planform evolution of the channel is documented with time lapse imagery. Images are acquired at a constant frequency with typical time steps of 1-3 seconds depending on the experiment. Inflow water temperature is measured with a common thermometer and ice block temperatures are measured with a handheld infrared thermometer. Approximate flow depths are measured with a periodontal probe during the run.

The experimental measurements are complemented with a mold of the channel made with a RoomTemperature-Vulcanizing (RTV) Silicone. Specifically, the two part silicone rubber used is Mold $\mathrm{Max}^{\mathrm{TM}} 30$ as the base and Fast $\mathrm{Cat}^{\mathrm{TM}} 30$ as the curing agent. Once the experiment is over, the block is tilted so that any remaining water drains out and then the block is put back inside the cooler and the cooler inside the chest freezer. After 24 hours, the block is taken out and laid on the 
floor. The silicone rubber is poured into the channel beginning from the lowest elevation areas and allowed to harden while the ice block melts. Since the silicone is poured into the channel soon after the ice block is removed from the freezer, the process, which at room temperature would take 30 minutes, extends for a few hours. The mold is recovered once the ice block melts completely.

\section{Millimeter Scale Experiments}

The mm-scale experiments were, at first, incidental. The channel resulting from a $\mathrm{cm}$-scale run was being molded and the mm-scale channels formed from thin meltwater flow generated by heat release from molding material as it hardened. Figure 3 shows the first set of channels observed by the authors. Following this discovery, the process was repeated to document the formation and evolution of the mm-scale channels.

Subsequent runs involved molding a cm-scale channel and letting the mm-scale channels form and evolve. The scale of the channels only allows measuring planform shapes with the help of images. Once the channels begin to form, dye is added over the surface at the upstream end of the channels and its downstream flow documented with images and in certain cases with video.

\section{Image Processing Methods}

The time-lapse images from the cm-scale runs were used to measure reach averaged flow velocities, average channel widths and lateral migration rates. Images were analyzed in MatLab with routines we specifically developed for this purpose.

Channel centerlines of meltwater meanders in laboratory and field images were manually digitized within MatLab. The $(x, y)$ coordinates of the centerlines were saved in two column text files containing as many rows as vertices used to digitize the centerline.

All length scales were measured in the images (in pixels) and converted to real length units using the corresponding resolution. Image resolution was determined by measuring a known distance in the image and associating the number of pixels to the known length value. Time difference between images was used to compute velocities and lateral migration rates.

Specifically, average channel widths were determined by measuring widths along the centerline at various stations and computing the mean value; lateral migration rates were determined by computing the displacement of the apex of a given meander bend at different times throughout the run and dividing by the corresponding time interval; and reach averaged velocities were 
determined by calculating the along-centerline distance traveled by injected dye fronts in subsequent images and dividing by the time between them.

\section{Use of the National Cooperative Highway Research Program (NCHRP) Meandering River Database}

Meandering river data in the NCHRP database (Lagasse et al., 2004) were used to compare the characteristics of meltwater meandering channels with those of alluvial rivers. For all rivers in the database, the following steps were conducted:

1. Open river files in ArcMap

2. Export river centerlines to a new feature class.

3. Extract river centerline coordinates and export them to an ASCII file.

4. Open ASCII files in Excel and make sure that centerline coordinates were sorted from upstream to downstream. Coordinate pairs were rearranged when this was not the case and files saved as text file again.

5. Meander sinuosities, average wavelengths and average widths were compiled and stored in a single text file in matrix form.

\section{Channel Centerline Preparation and Analysis}

All channel centerlines were prepared and analyzed in MatLab as follows:

1. Load text file with channel centerline coordinates.

2. Translate the coordinates of the reach so that the upstream most node in the reach is located at the origin of the Cartesian plane. This requires subtracting all coordinate pair values to those of the upstream most node as:

$$
x_{i}^{*}=x_{i}-x_{1} \text { and } y_{i}^{*}=y_{i}-y_{1}
$$

$\left(x_{i}^{*}, y_{i}^{*}\right)$ correspond to the translated centerline coordinates; $\left(x_{i}, y_{i}\right)$ represents any coordinate pair along the original centerline with $i=1,2, \ldots N$ where $N$ is the total number of vertices and $\left(x_{1}, y_{1}\right)$ are the original coordinates of the upstream most node in the reach. After this step, $\left(x_{1}^{*}, y_{1}^{*}\right)=(0,0)$.

3. Compute the direction (angle) series for the centerline as:

$$
\theta_{i}=\operatorname{atan} 2\left(y_{i}^{*}, x_{i}^{*}\right)
$$


$\theta_{i}=$ direction (angle) between the horizontal and the segment that connects the origin and the coordinates $\left(x_{i}^{*}, y_{i}^{*}\right)$. It is computed with atan2, the four-quadrant inverse tangent which returns values in the closed interval $[-\pi, \pi]$.

4. Standardize the direction series so that its average value over the entire reach is equal to zero. This requires computing new coordinates as:

$$
x_{i}^{\prime}=x_{i}^{*} \cdot \cos \left(\theta_{i}-\bar{\theta}\right) \text { and } y_{i}^{\prime}=y_{i}^{*} \cdot \sin \left(\theta_{i}-\bar{\theta}\right)
$$

$\left(x_{i}^{\prime}, y_{i}^{\prime}\right)$ are the centerline coordinates for which the average of the direction series is zero, and $\bar{\theta}$ is the average value of the original direction series.

5. Smooth centerline at half channel width intervals using the method developed by Güneralp and Rhoads (2008). This method outputs $\boldsymbol{X}^{*}, \boldsymbol{Y}^{*}, \boldsymbol{C}^{*}$ and $\boldsymbol{S}^{*}$ where $\boldsymbol{X}^{*}$ and $\boldsymbol{Y}^{*}$ are vectors holding the coordinates of the smoothed centerline, $\boldsymbol{C}^{*}$ is the curvature series vector and $\boldsymbol{S}^{*}$ is the vector of streamwise (along channel) coordinates.

6. Make all four series output in the previous step dimensionless as shown below:

$$
\begin{gathered}
(\boldsymbol{X}, \boldsymbol{Y}, \boldsymbol{S})=\left(\boldsymbol{X}^{*}, \boldsymbol{Y}^{*}, \boldsymbol{S}^{*}\right) \cdot B^{-1} \\
\boldsymbol{C}=\boldsymbol{C}^{*} B
\end{gathered}
$$

$B$ is the channel width, $(\boldsymbol{X}, \boldsymbol{Y})$ are vectors of dimensionless centerline coordinates, $\boldsymbol{S}$ is the dimensionless streamwise coordinates vector and $\boldsymbol{C}$ is the dimensionless curvature series.

7. Compute the fatness and skewness using the method developed by Vermeulen et al. (2016).

\section{Section S2: Meltwater Channels}

(Images in following pages) 
Images showing digitized centerlines for the mm-scale experiments, and the Peterman Ice Island image.

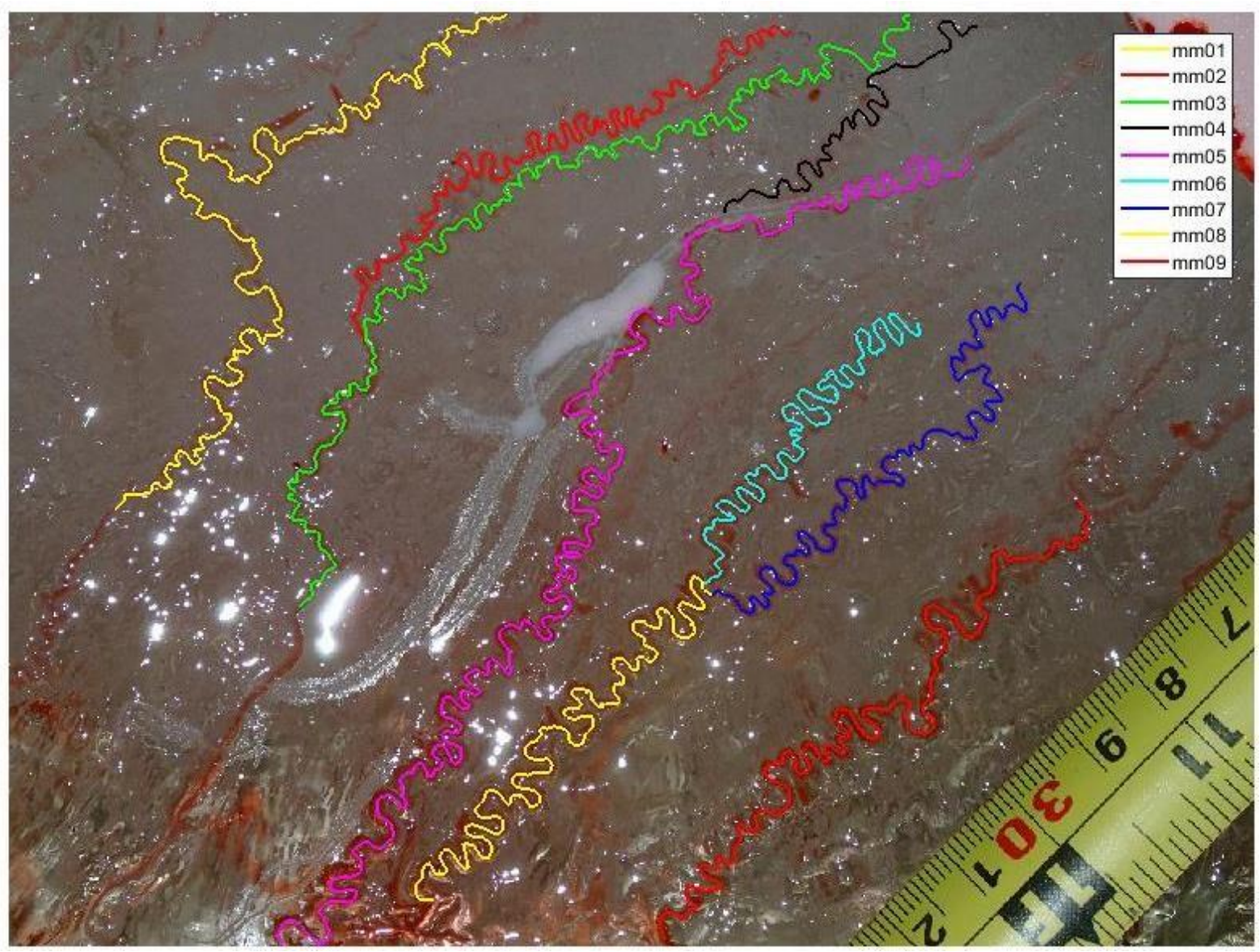

Figure S2.1. First set of mm-scale digitized channel centerlines. From top-left to bottom-right, channels correspond to $\mathrm{mm} 01$ to $\mathrm{mm} 09$. 


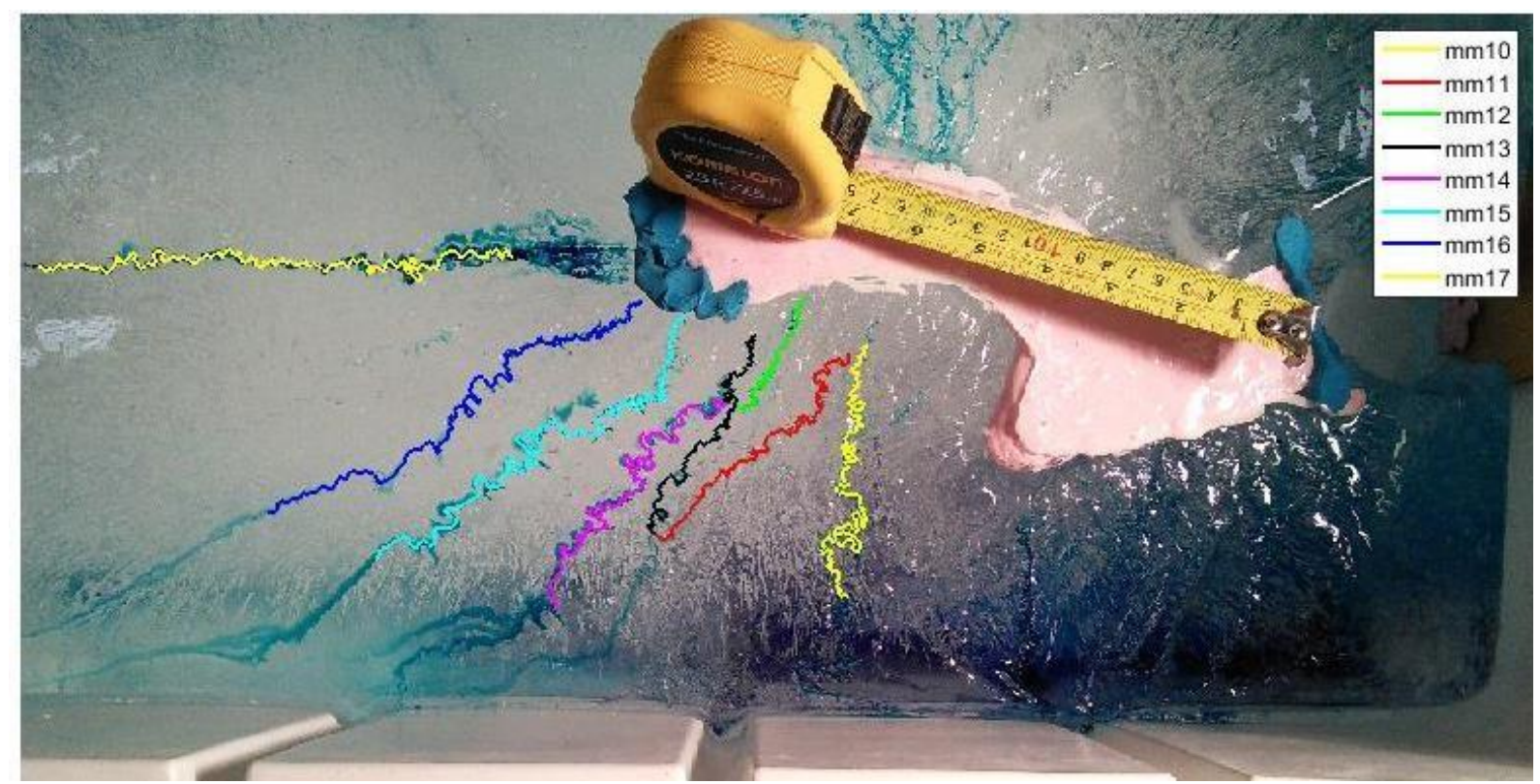

Figure S2.2. Second set of mm-scale digitized channel centerlines. From bottom-right to top-left, channels correspond to mm10 to $\mathrm{mm} 17$.

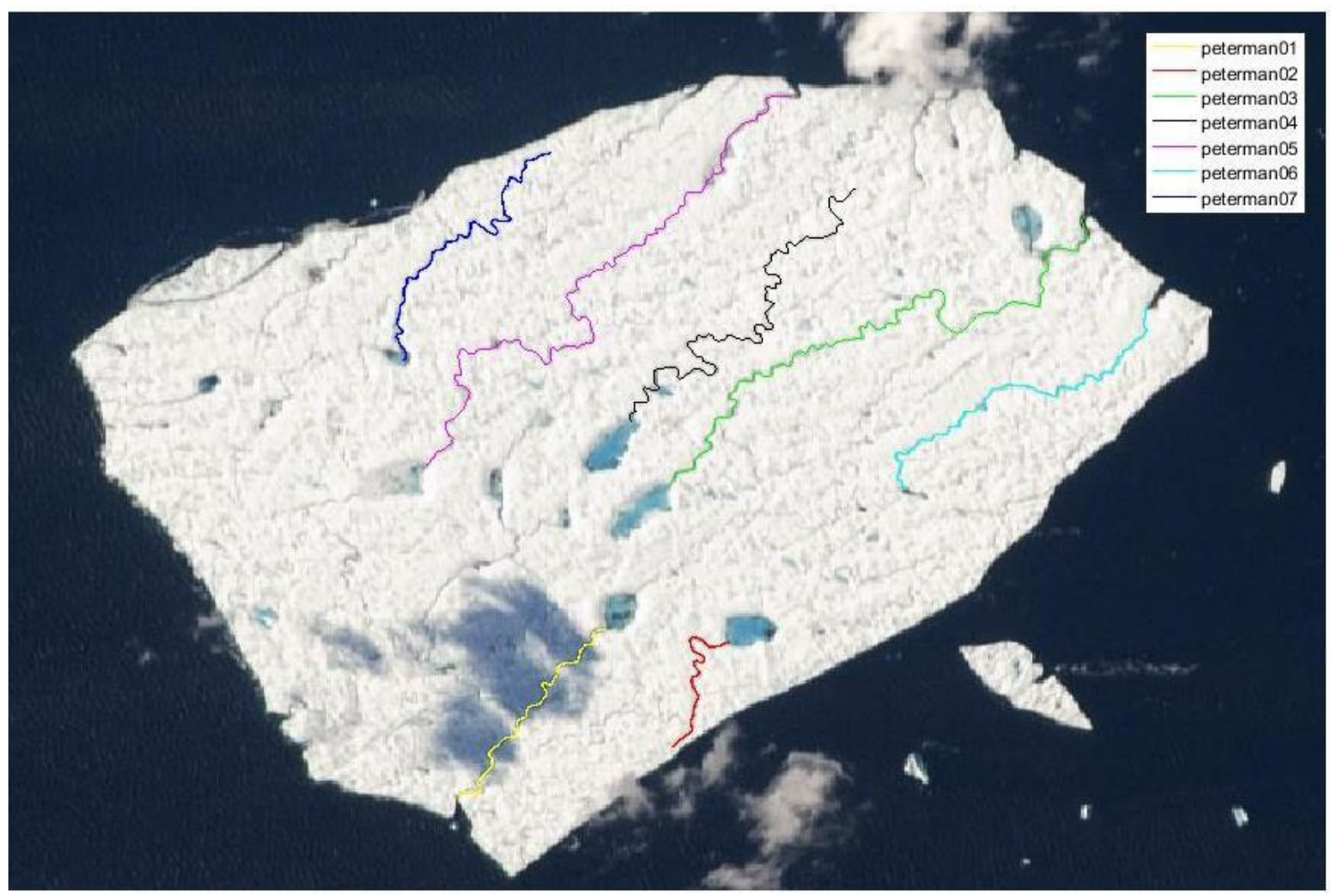

Figure S2.3. Digitized meltwater meandering channels over Peterman Ice Island. Source: ISS Crew Earth Observations experiment and Image Science \& Analysis Laboratory, Johnson Space Center. 
Centimeter-scale meandering rivulet images used for planform evolution analysis

Roberto Fernández

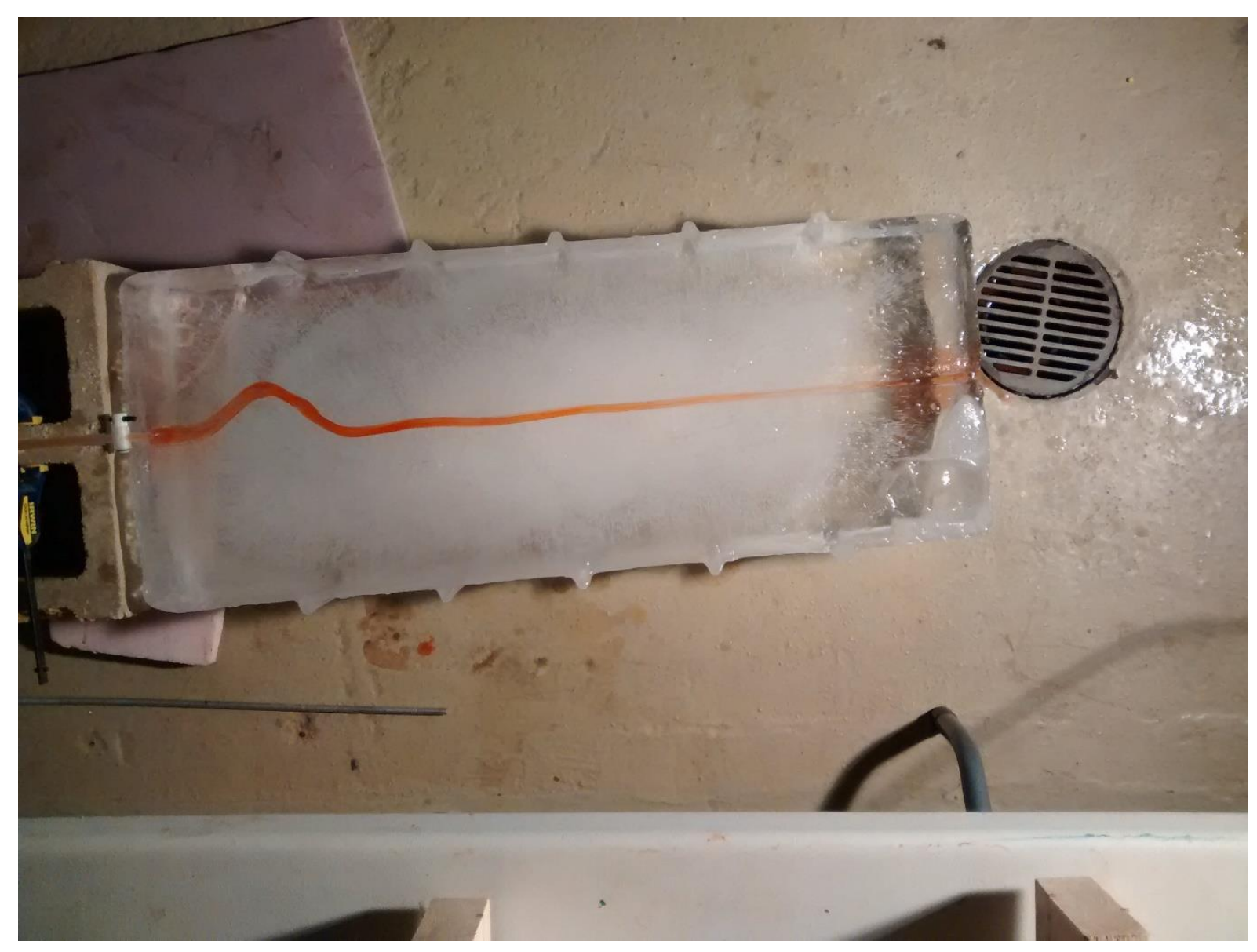

Run $01-\mathrm{t}=0 \min$ 


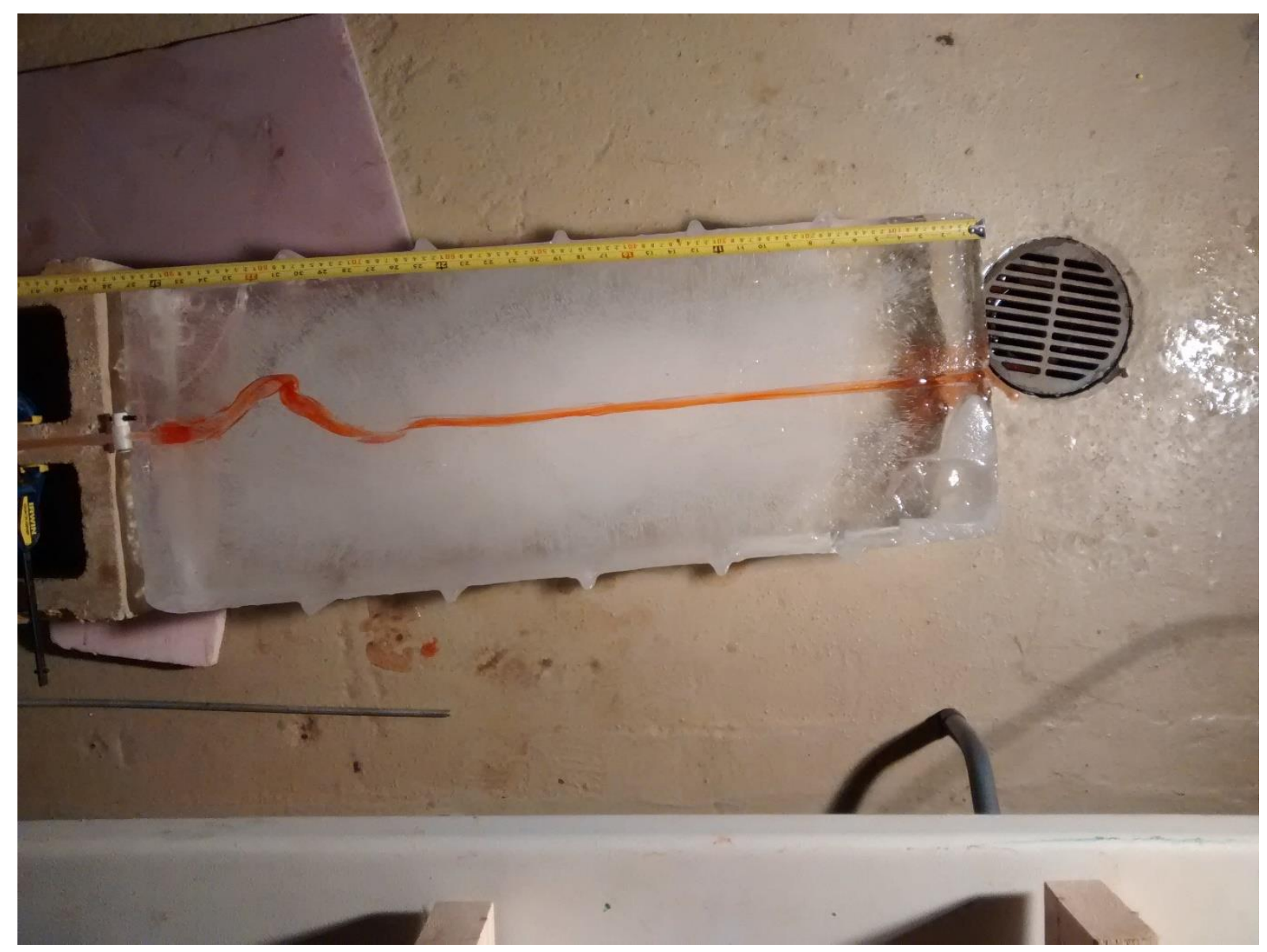

Run $01-\mathrm{t}=7 \mathrm{~min}$ 


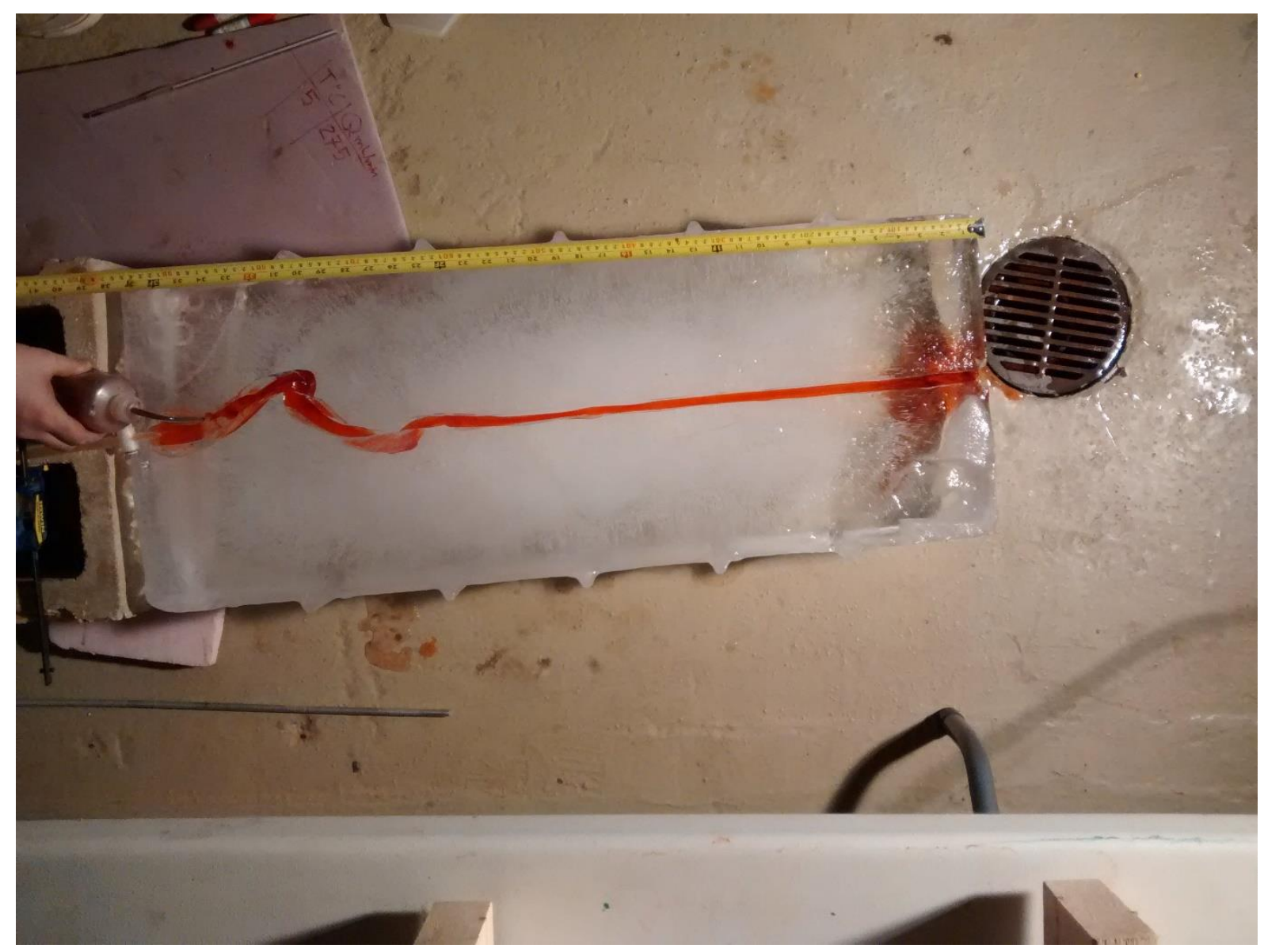

Run $01-t=20 \min$ 


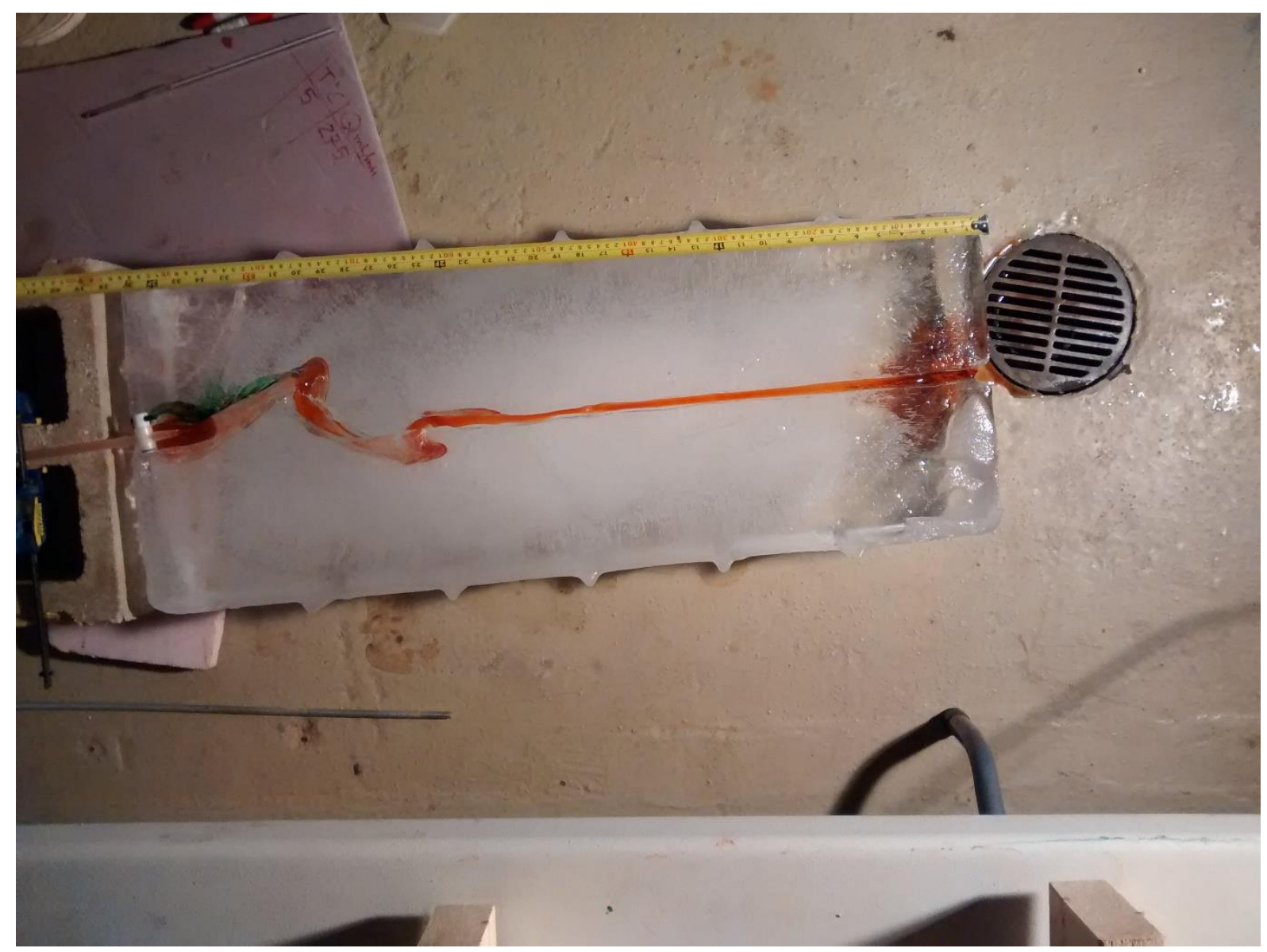

Run $01-t=35.5 \min$ 


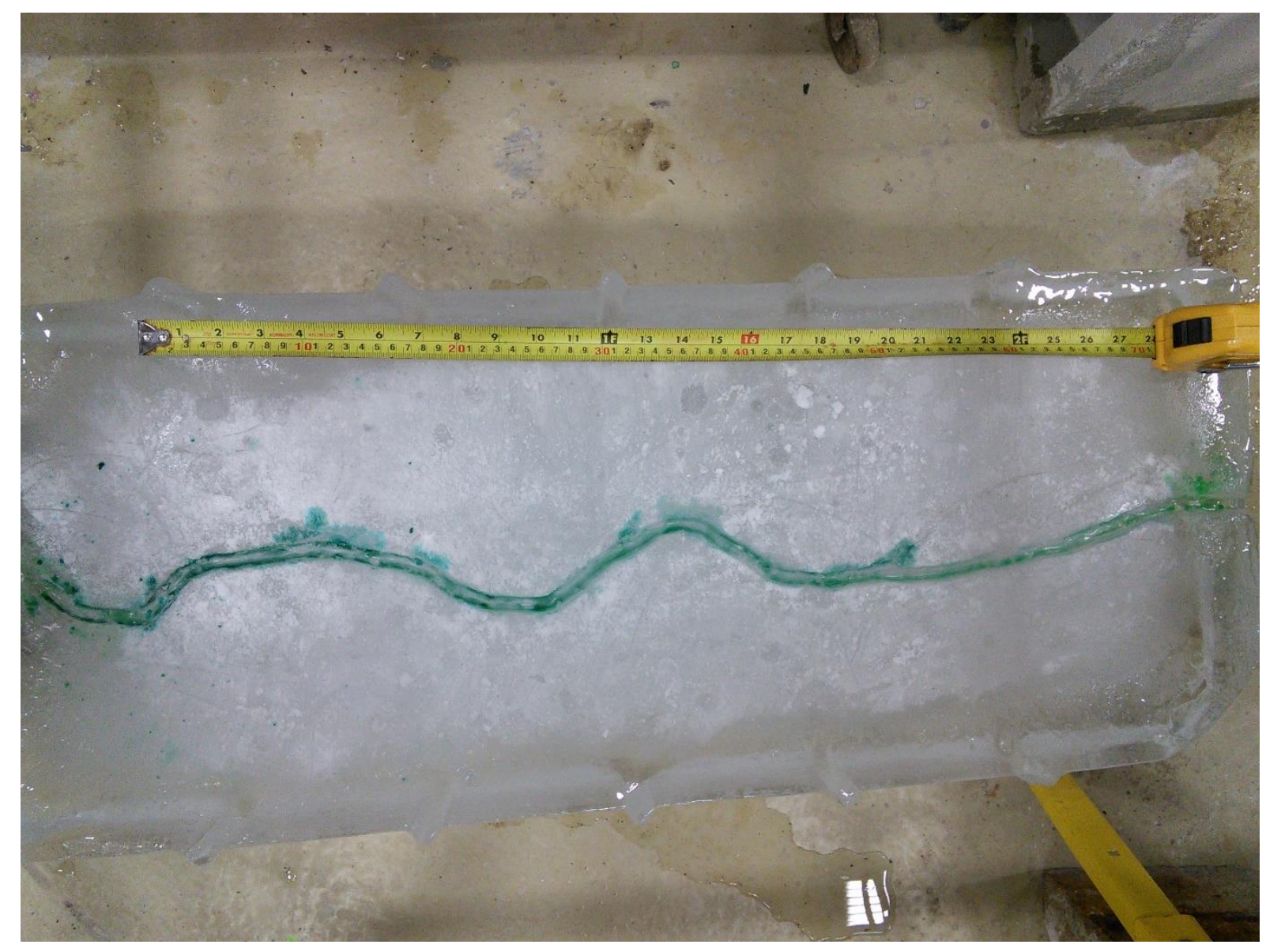

Run $02-\mathrm{t}=0 \mathrm{~min}$ 


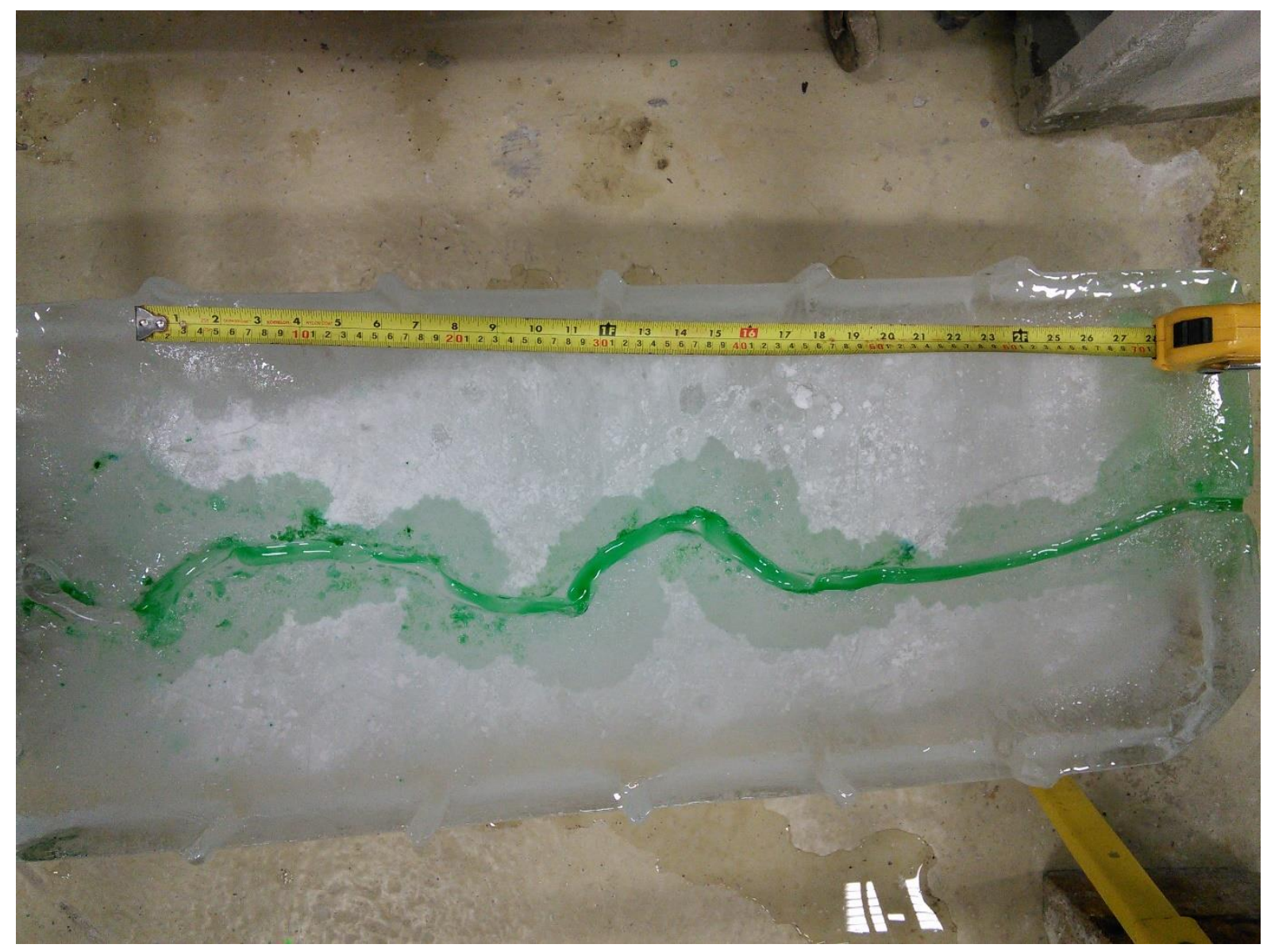

Run $02-t=4.6 \min$ 


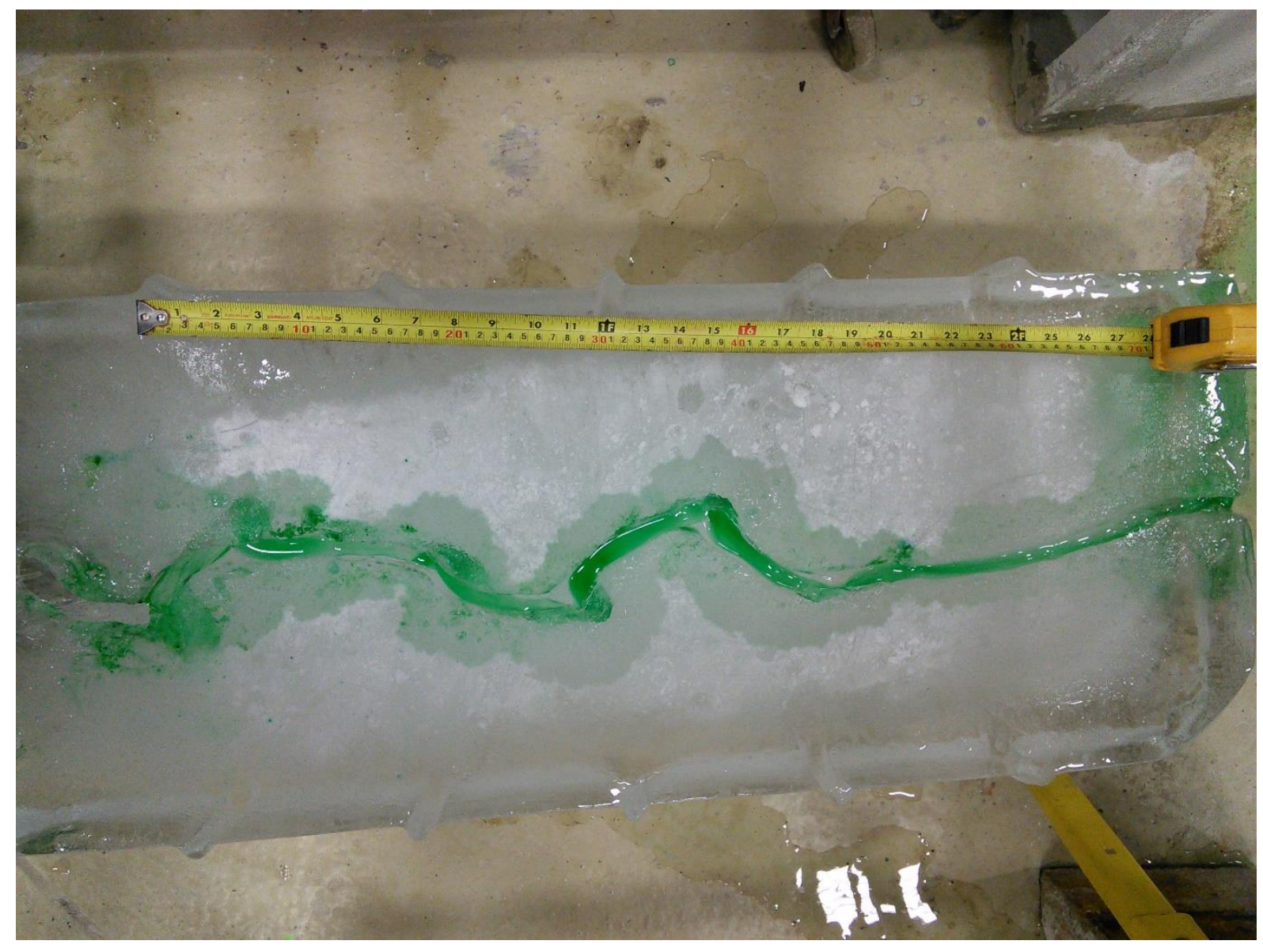

Run $02-\mathrm{t}=9.8 \mathrm{~min}$ 


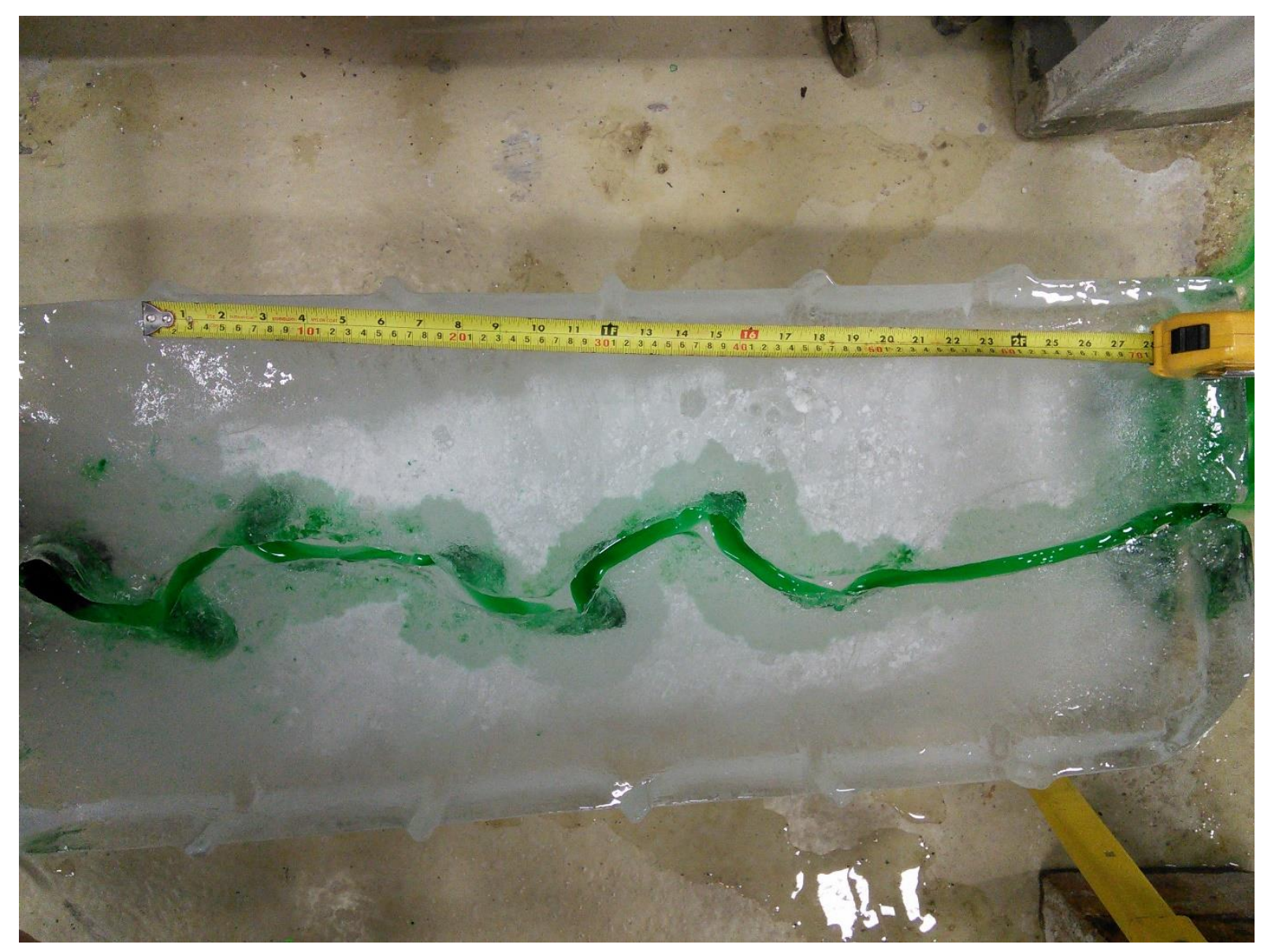

Run $02-\mathrm{t}=12.4 \mathrm{~min}$ 


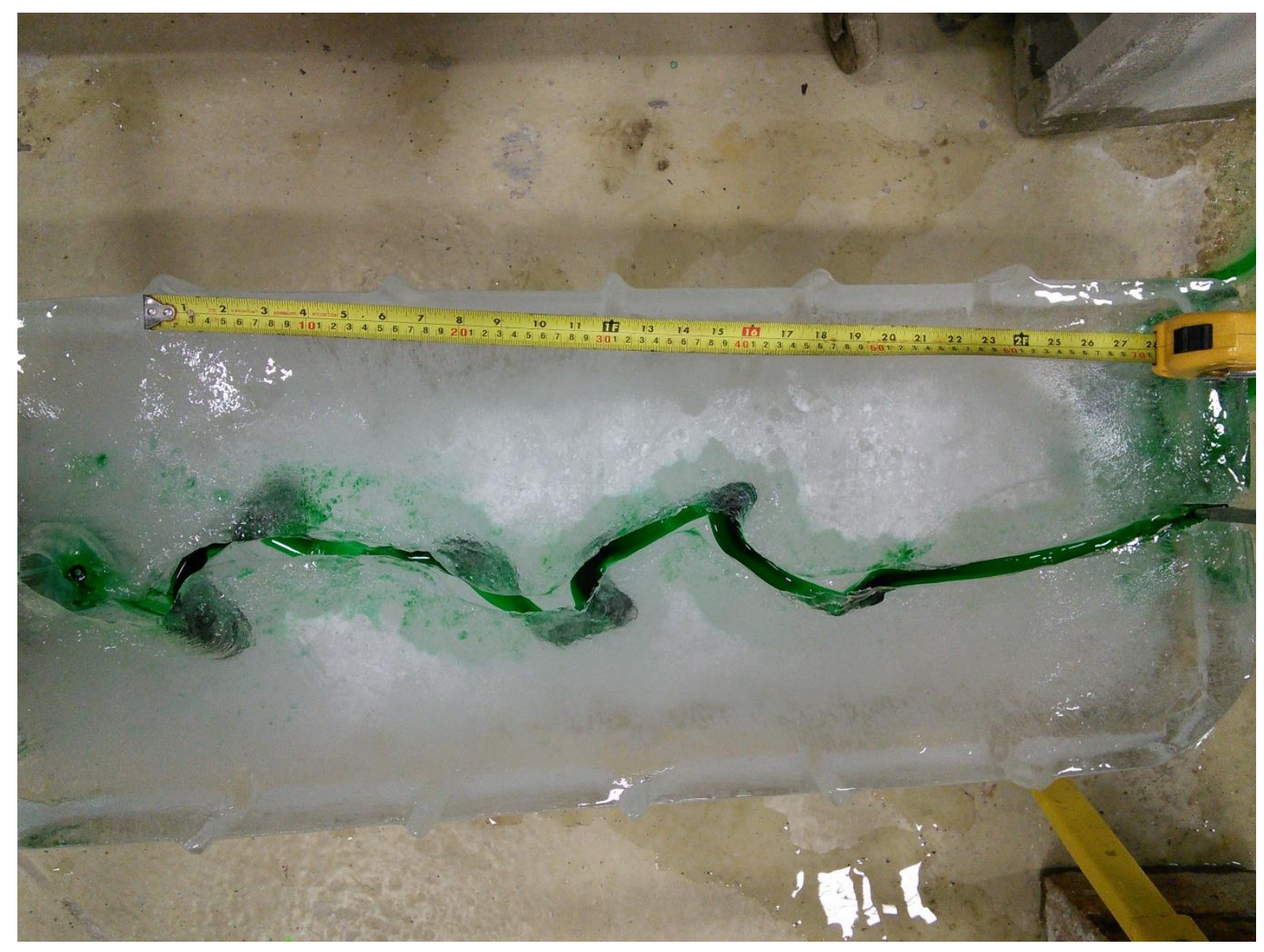

Run $02-t=14.4 \min$ 


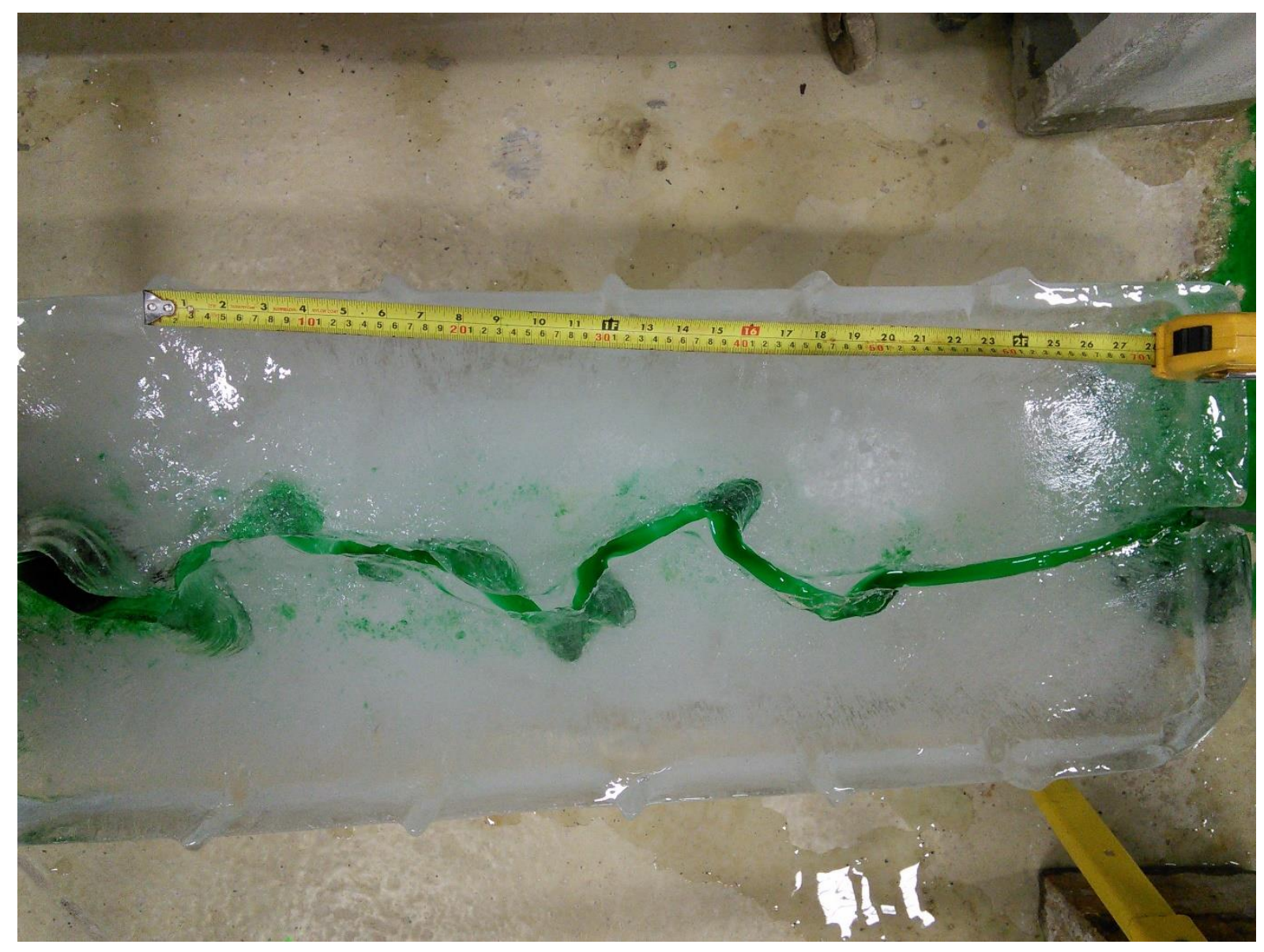

Run $02-\mathrm{t}=18.8 \mathrm{~min}$ 


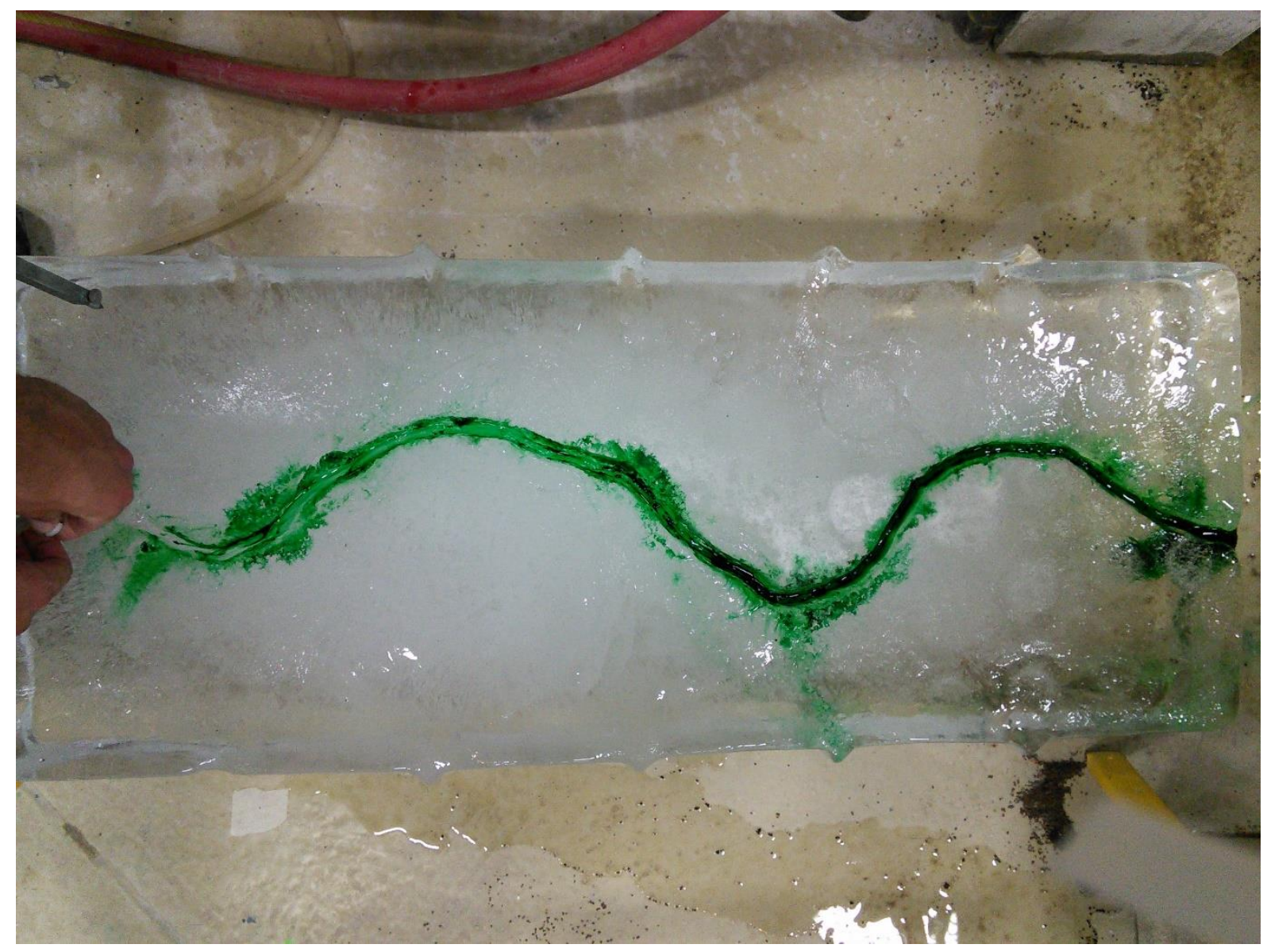

Run $03-\mathrm{t}=0 \mathrm{~min}$ 


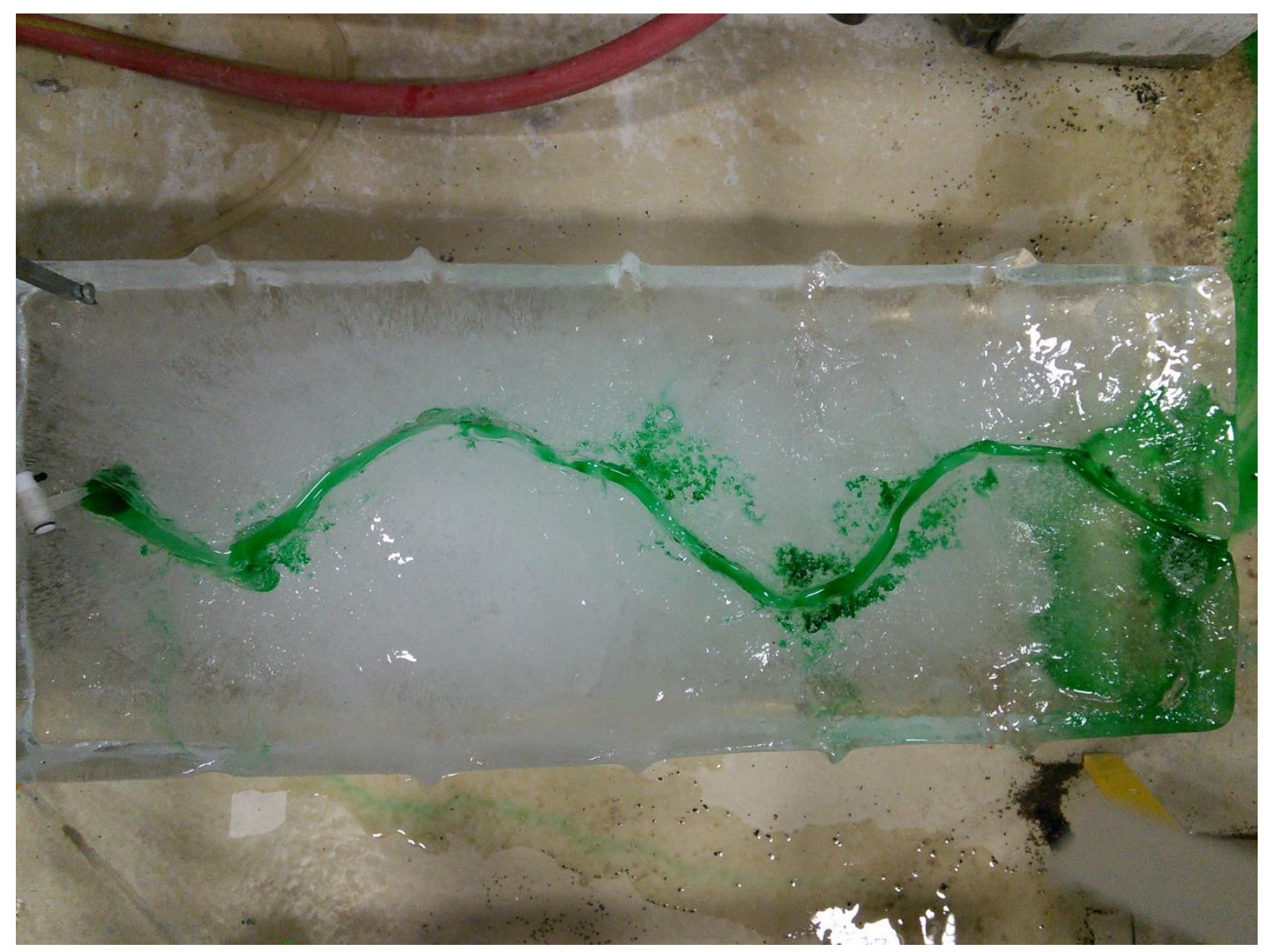

Run $03-\mathrm{t}=4.7 \mathrm{~min}$ 


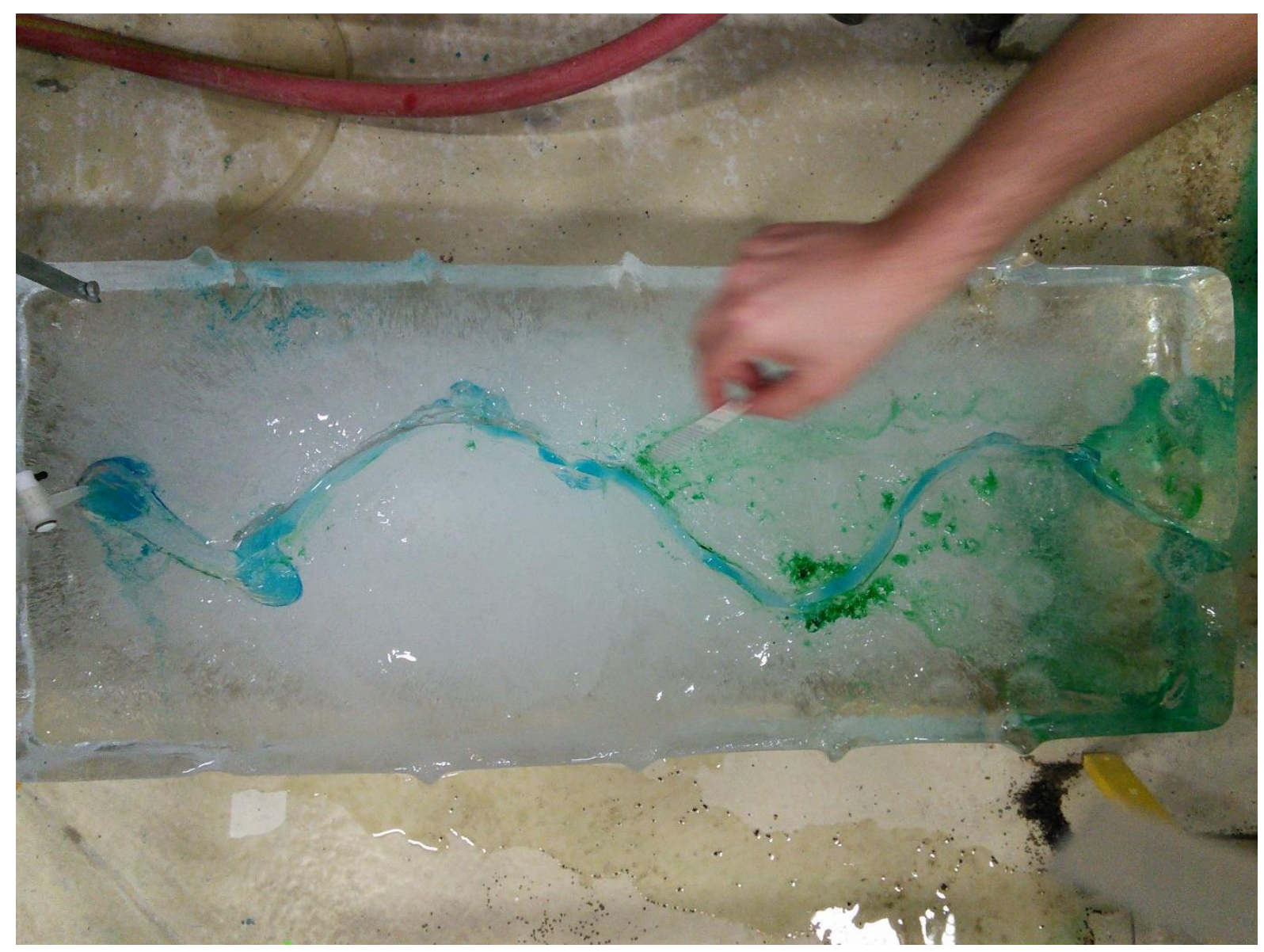

Run $03-\mathrm{t}=10.5 \mathrm{~min}$ 


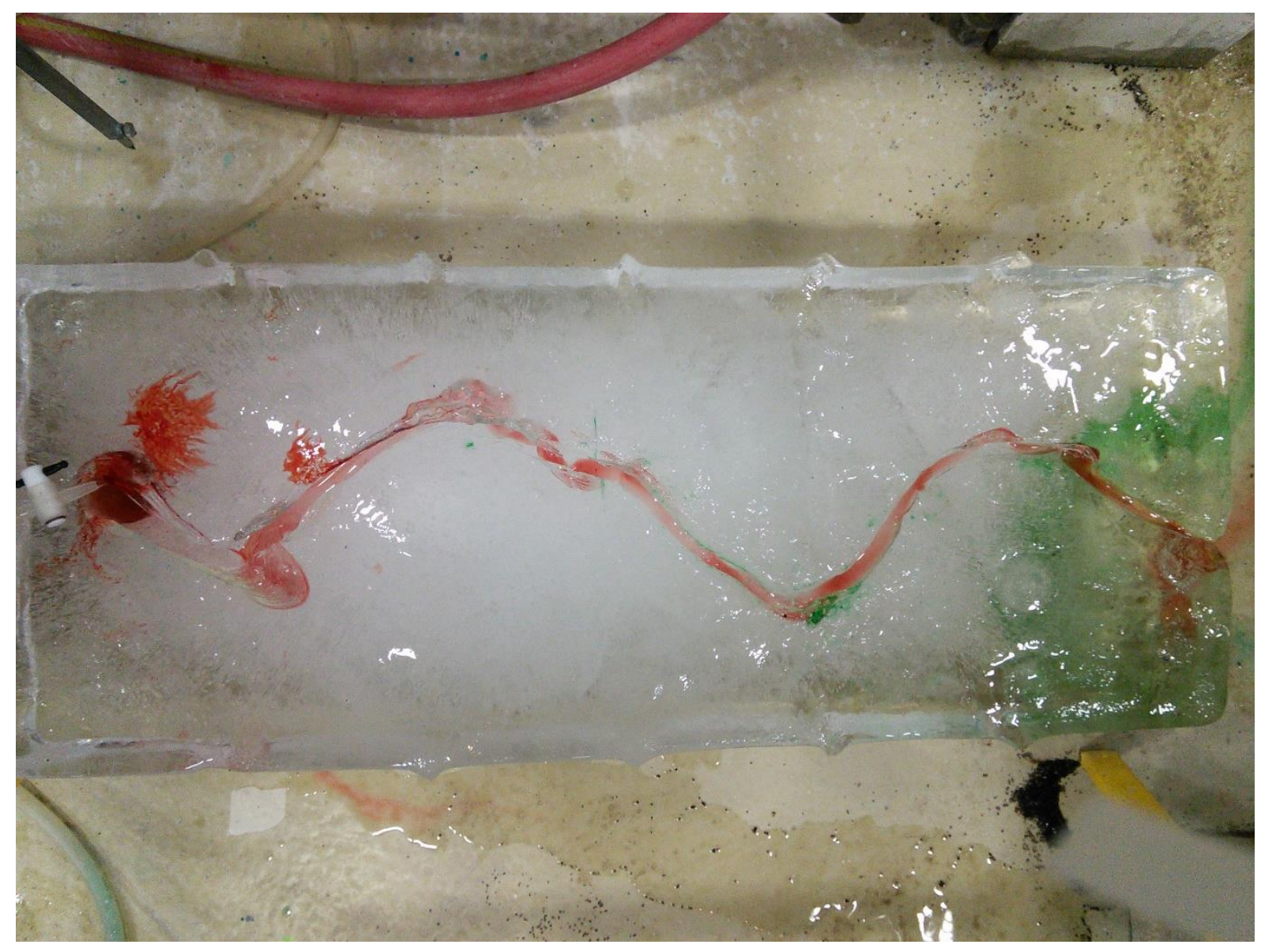

Run $03-t=15.2 \min$ 


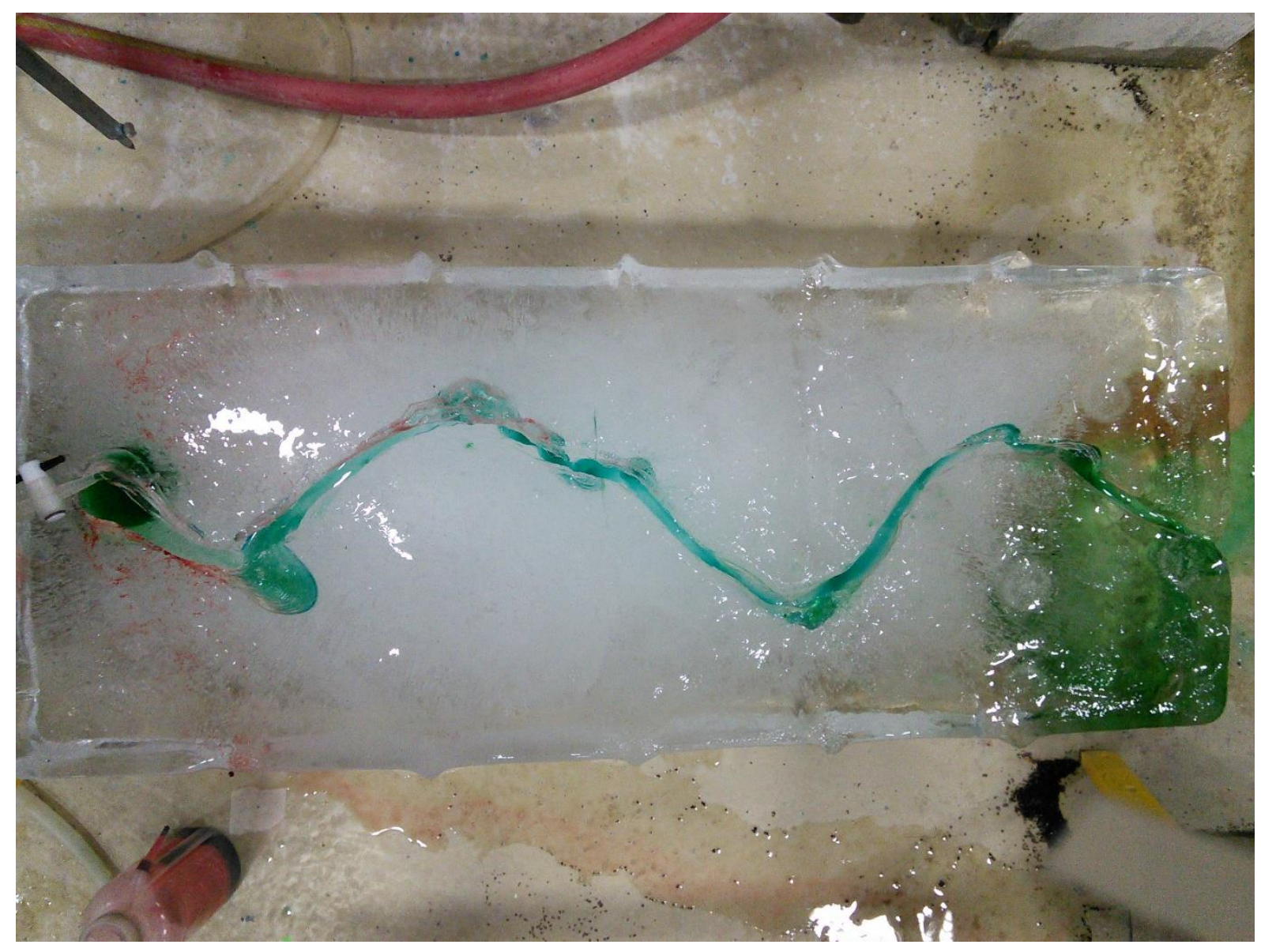

Run $03-\mathrm{t}=21.6 \mathrm{~min}$ 


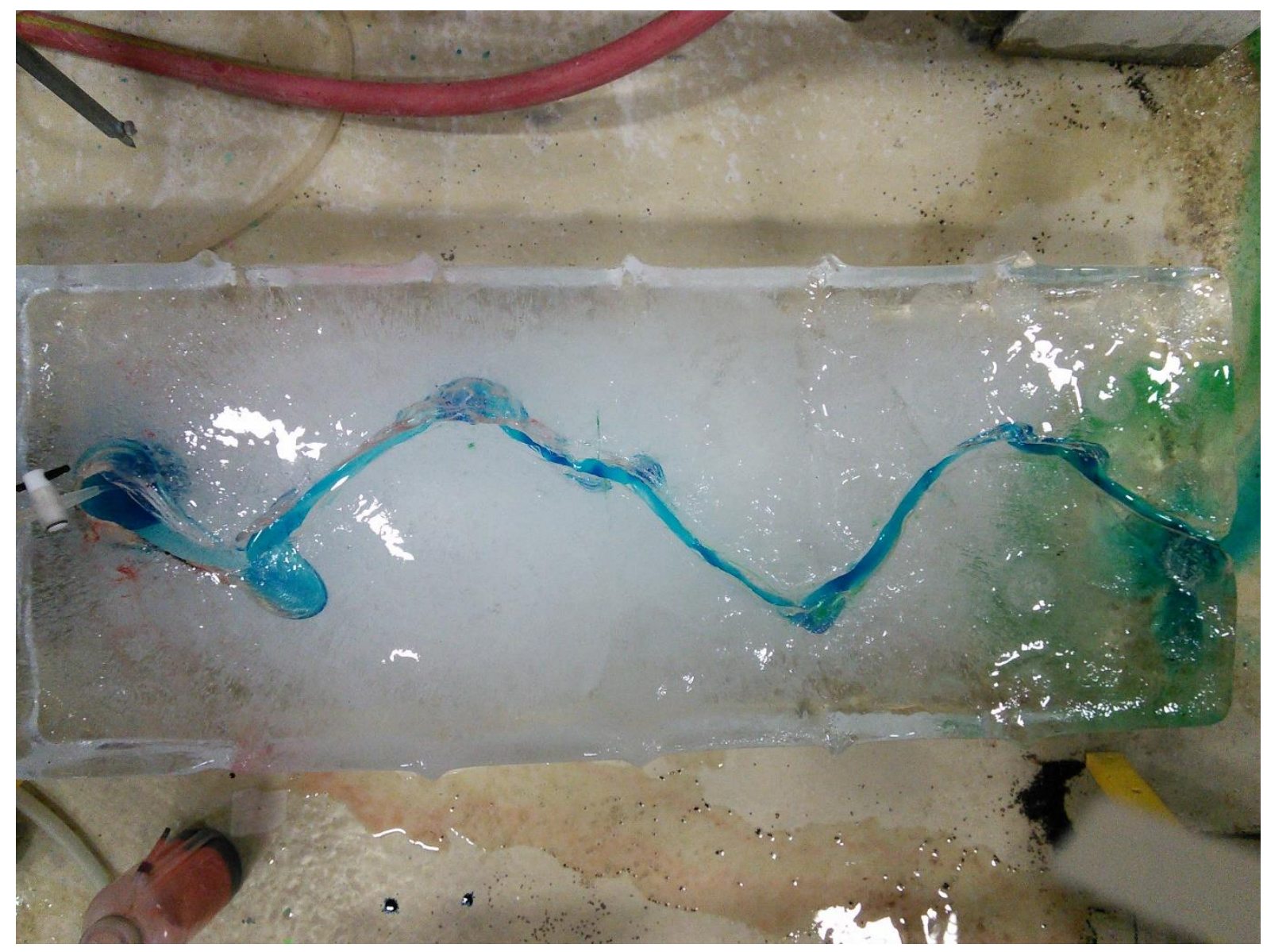

Run $03-\mathrm{t}=28.8 \mathrm{~min}$ 


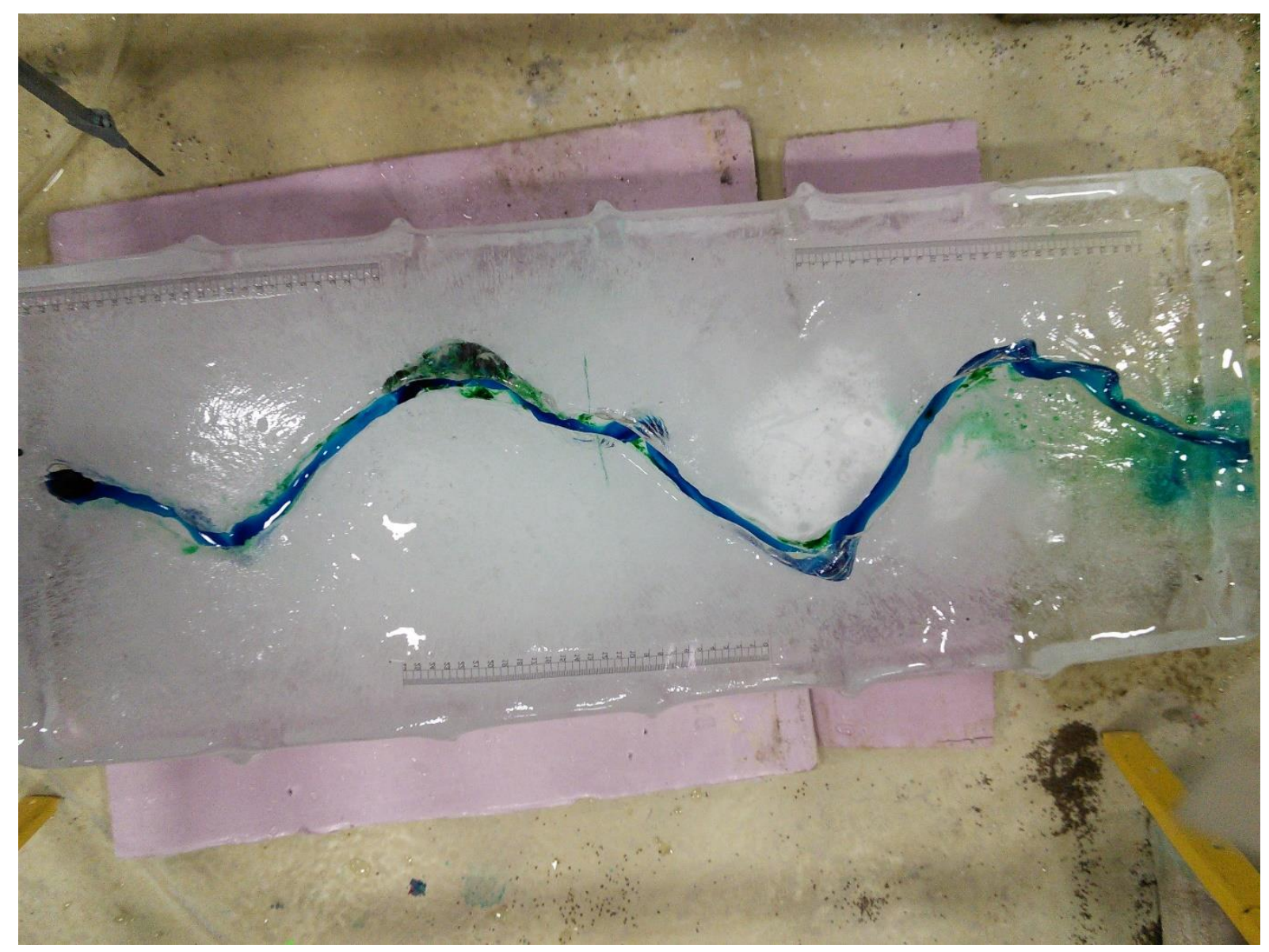

Run $04-\mathrm{t}=4 \min$ 


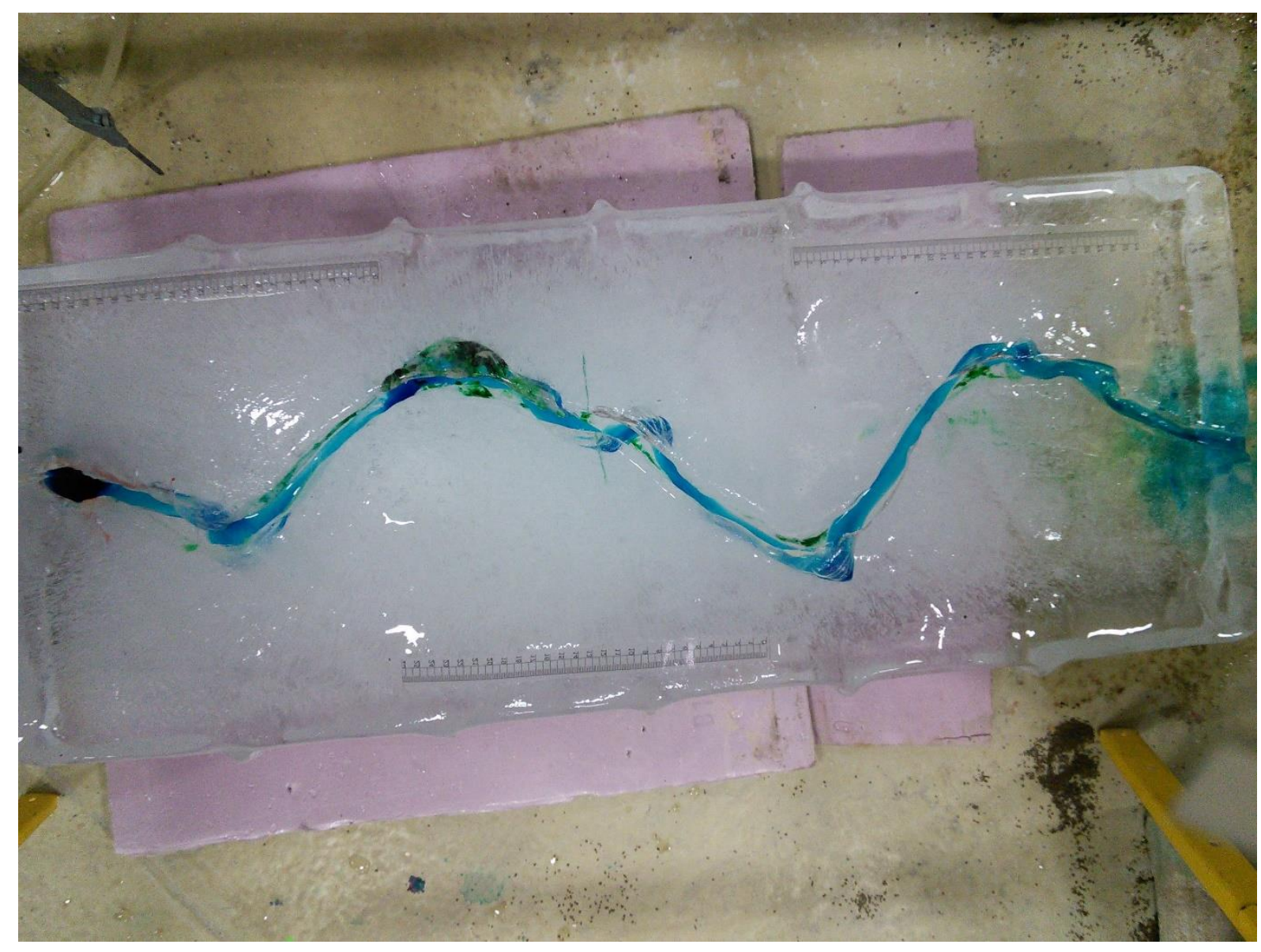

Run $04-\mathrm{t}=7.7 \mathrm{~min}$ 


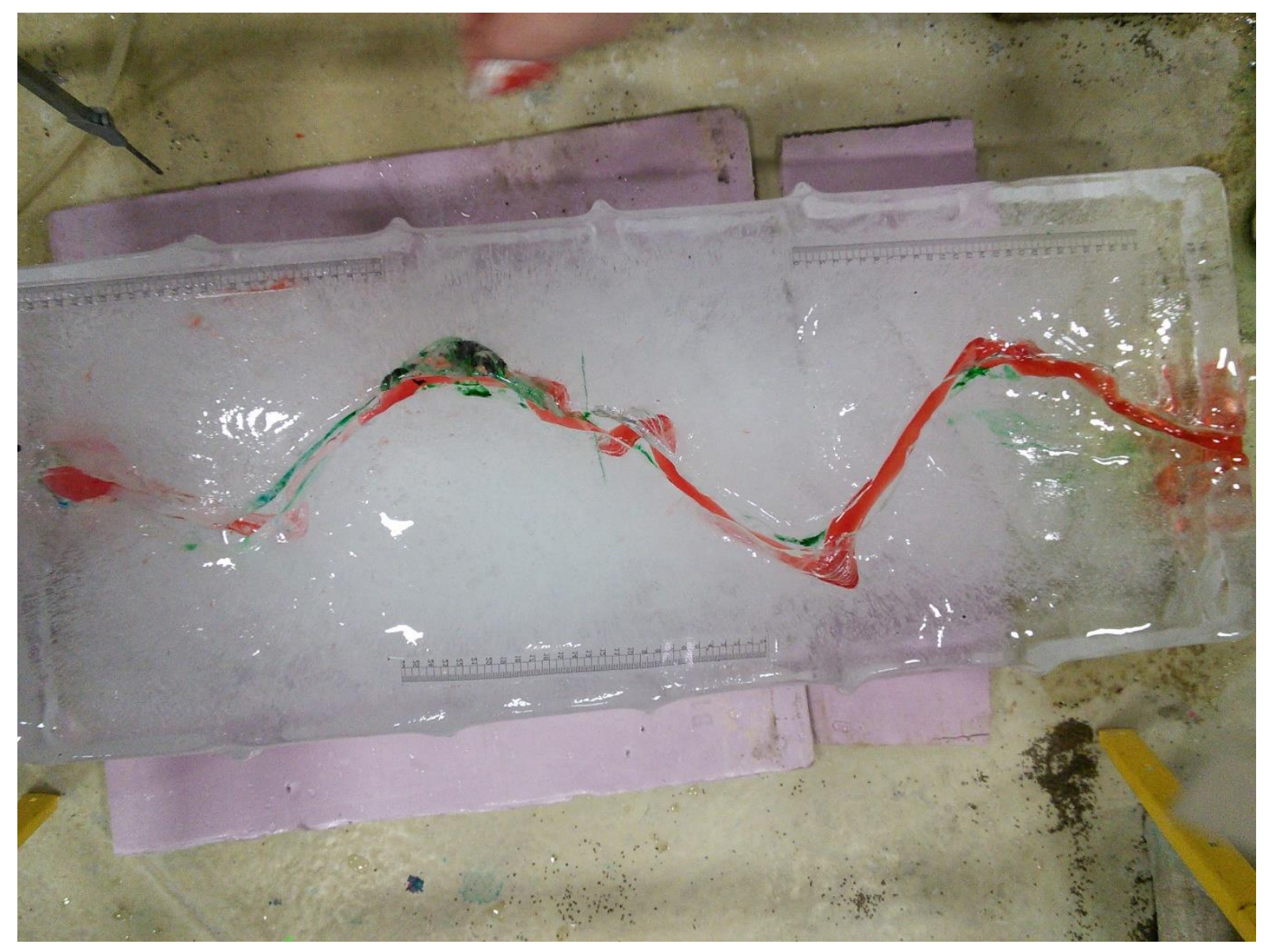

Run $04-\mathrm{t}=11.1 \mathrm{~min}$ 


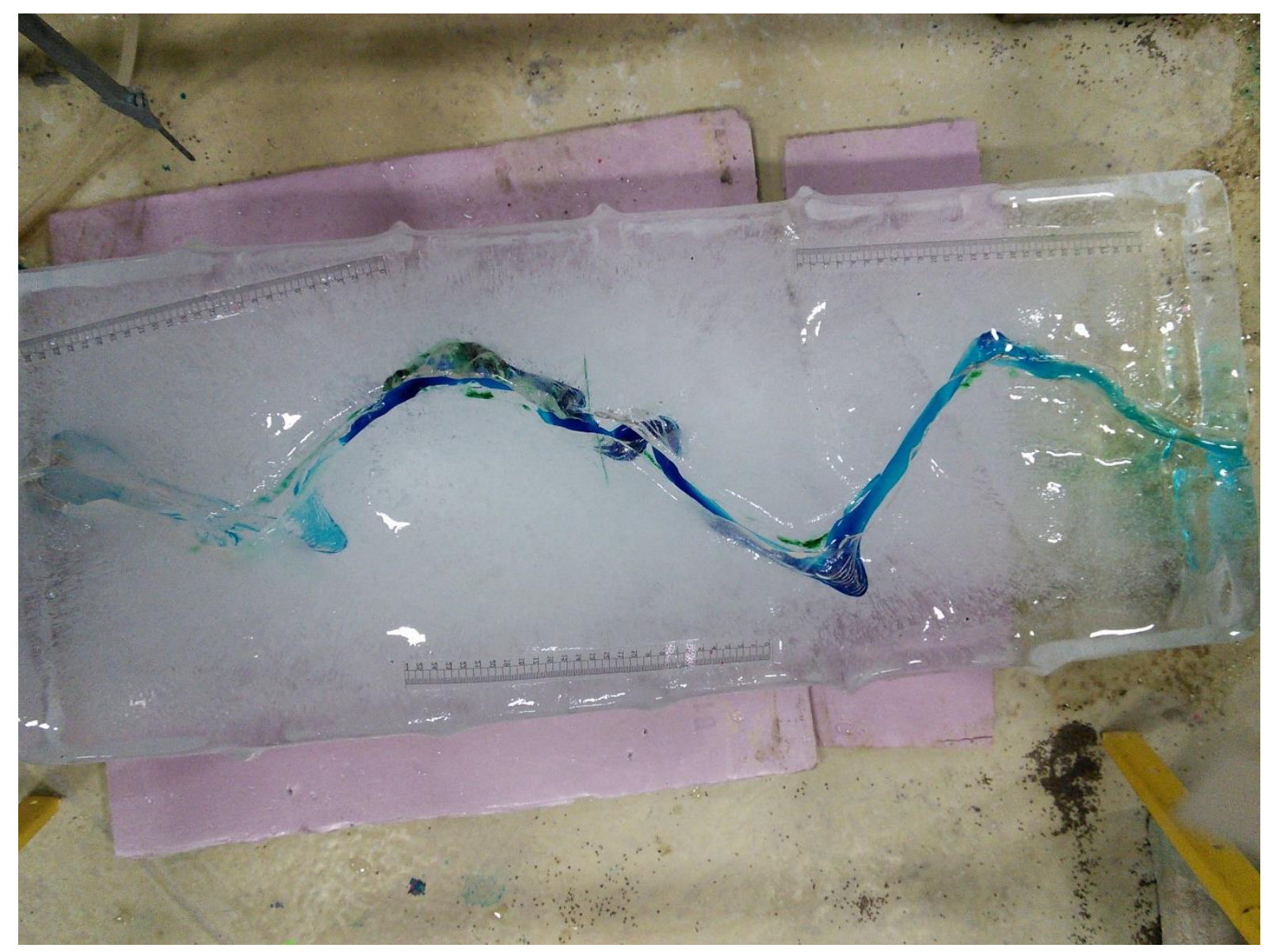

Run $04-t=14.4 \min$ 


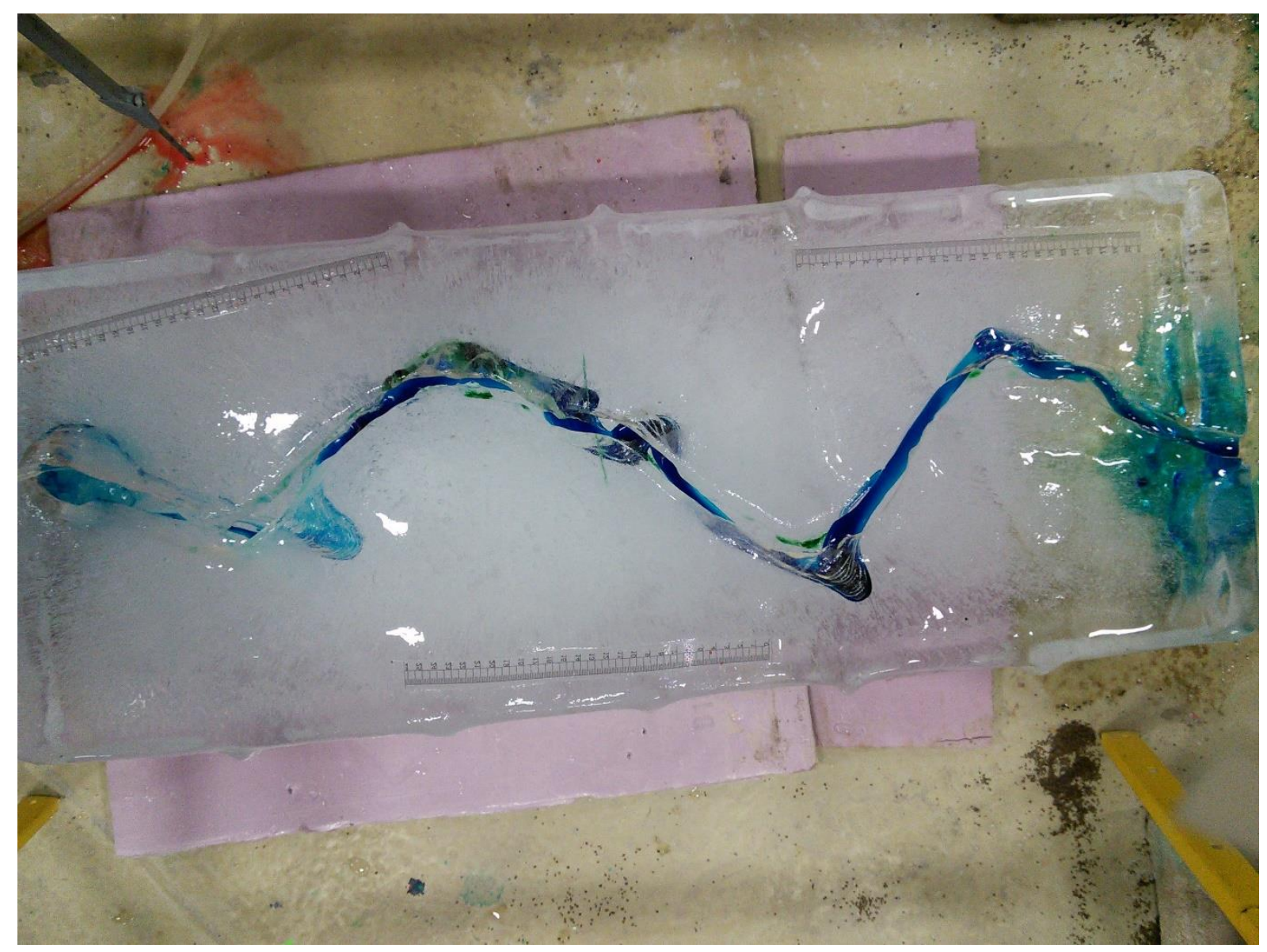

Run $04-t=18.8 \min$ 


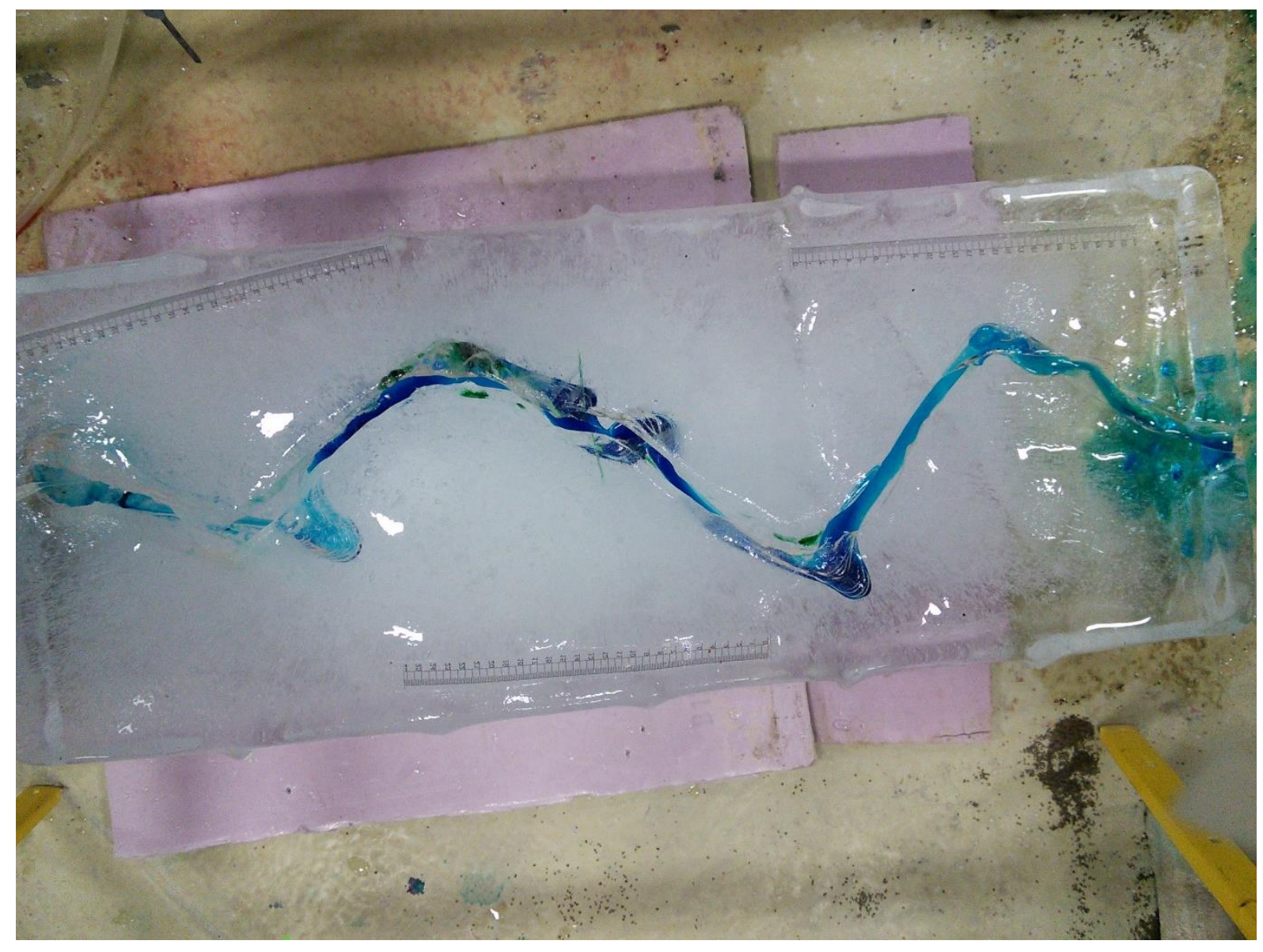

Run $04-21.4$ min 


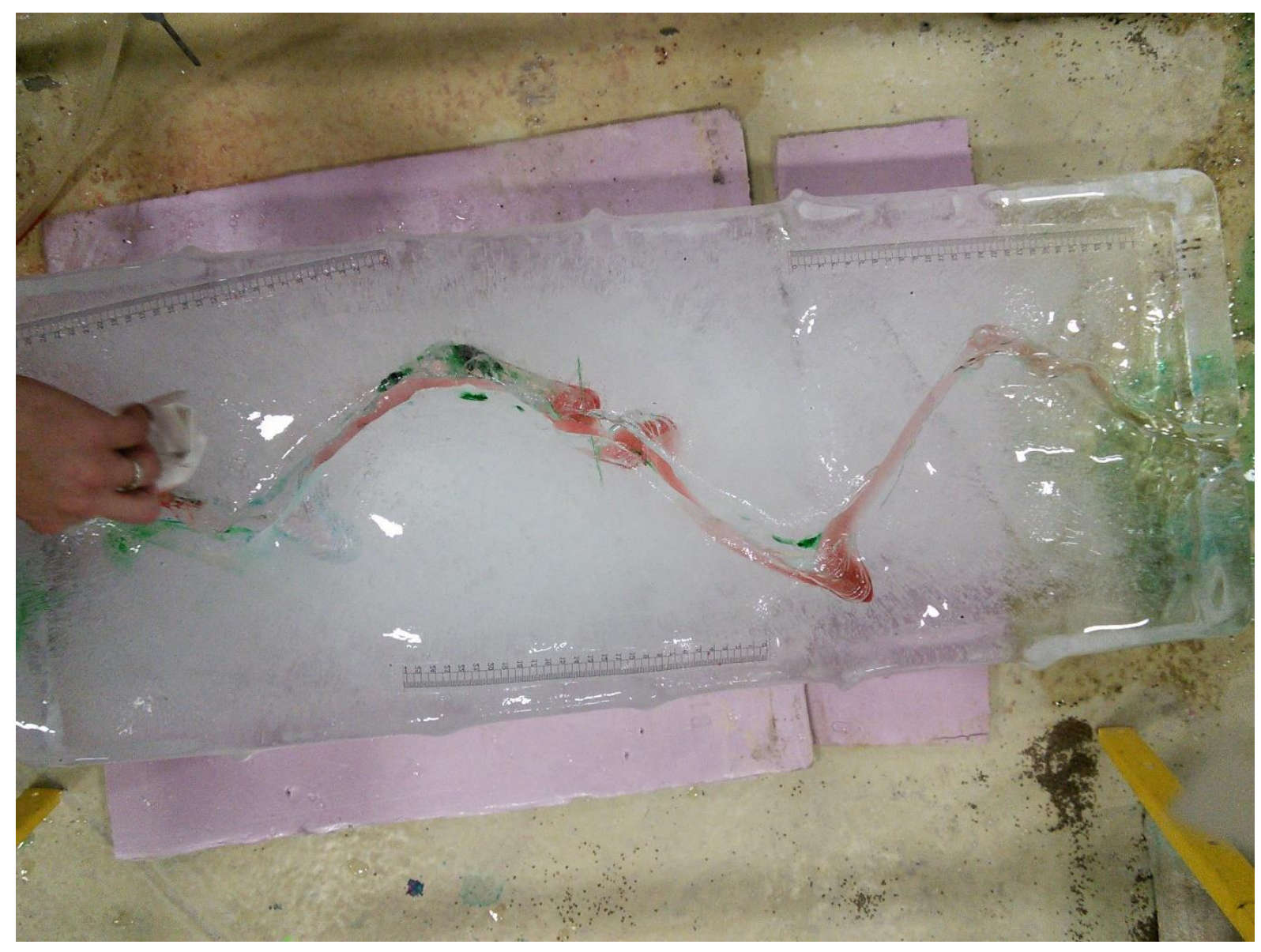

Run $04-\mathrm{t}=24.1 \mathrm{~min}$ 


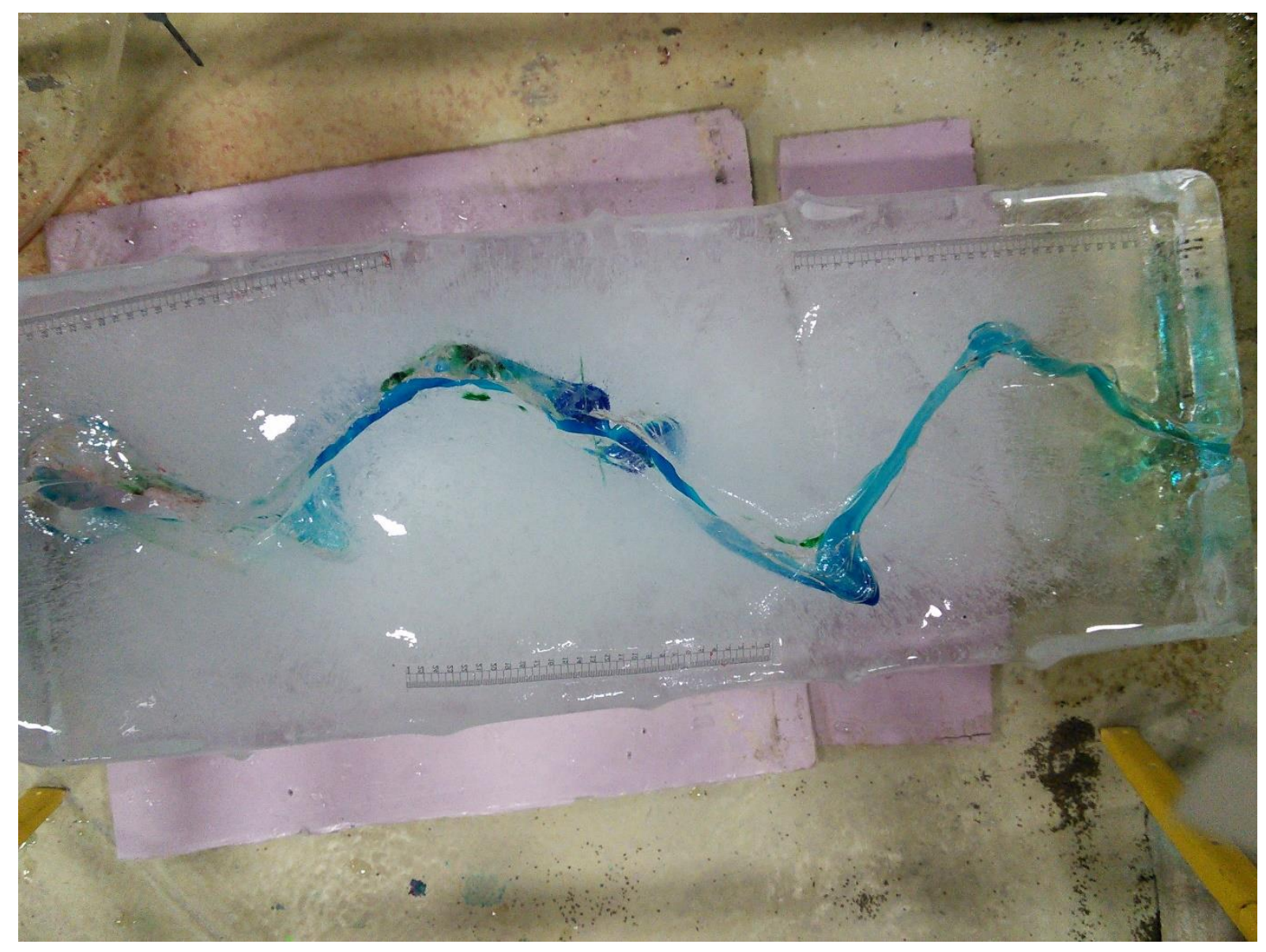

Run $04-t=27.1 \mathrm{~min}$ 


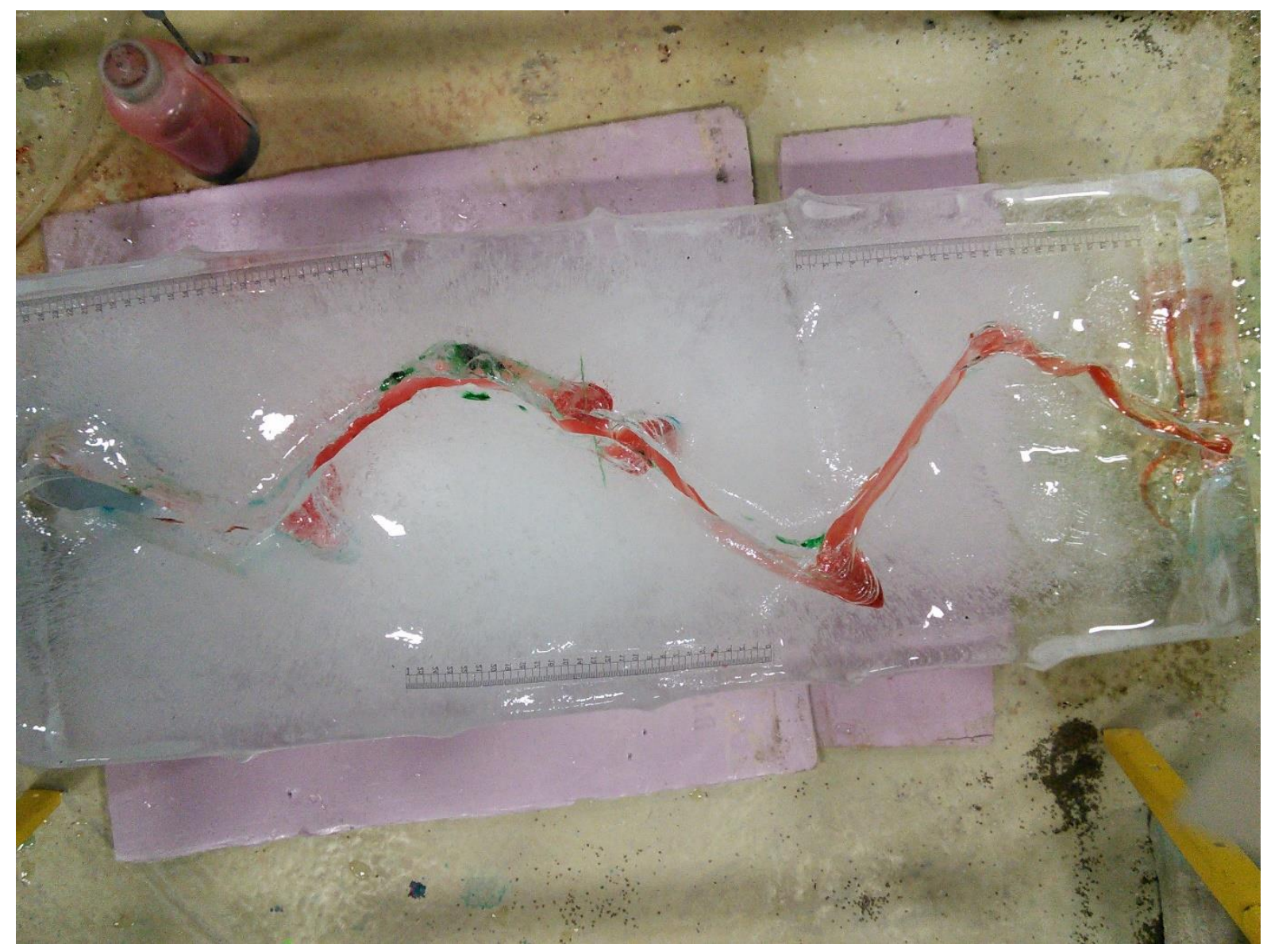

Run $04-t=28.8 \min$ 